the

abdus salam

international

centre

for theoretical

physics

PREDICTABILITY EXPERIMENTS FOR THE ASIAN SUMMER MONSOON:

IMPACT OF SST ANOMALIES ON INTERANNUAL AND INTRASEASONAL VARIABILITY

Franco Molteni

Susanna Corti

Laura Ferranti

and

Julia M. Slingo

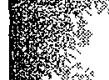


United Nations Educational Scientific and Cultural Organization and

International Atomic Energy Agency

THE ABDUS SALAM INTERNATIONAL CENTRE FOR THEORETICAL PHYSICS

\title{
PREDICTABILITY EXPERIMENTS FOR THE ASIAN SUMMER MONSOON: IMPACT OF SST ANOMALIES ON INTERANNUAL AND INTRASEASONAL VARIABILITYY ${ }^{1}$
}

\author{
Franco Molteni ${ }^{2}$ \\ The Abdus Salam International Centre for Theoretical Physics, Trieste, Italy, \\ Susanna Corti \\ Institute of Atmospheric Sciences and Climate ISAC-CNR, Bologna, Italy, \\ Laura Ferranti \\ European Centre for Medium-range Weather Forecasts, Reading, United Kingdom \\ and \\ Julia M. Slingo \\ NERC Centre for Global Atmospheric Modelling, University of Reading, United Kingdom.
}

MIRAMARE - TRIESTE

July 2003

\footnotetext{
${ }^{1}$ Journal of Climate, in press.

${ }^{2}$ Corresponding author: moltenif@ictp.trieste.it
} 


\begin{abstract}
The effects of SST anomalies on the interannual and intraseasonal variability of the Asian summer monsoon have been studied by multivariate statistical analyses of $850-\mathrm{hPa}$ wind and rainfall fields simulated in a set of ensemble integrations of the ECMWF atmospheric GCM, referred to as the PRISM experiments. The simulations used observed SSTs (PRISM-O), covering 9 years characterised by large variations of the ENSO phenomenon in the 1980's and the early 1990's. A parallel set of simulations was also performed with climatological SSTs (PRISM-C), thus enabling the influence of SST forcing on the modes of interannual and intraseasonal variability to be investigated.
\end{abstract}

As in observations, the model's interannual variability is dominated by a zonally-oriented mode which describes the north-south movement of the tropical convergence zone (TCZ). This mode appears to be independent of SST forcing and its robustness between the PRISM$\mathrm{O}$ and PRISM-C simulations suggests that it is driven by internal atmospheric dynamics. On the other hand, the second mode of variability, which again has a good correspondence with observed patterns, shows a clear relationship with the ENSO cycle. Since the mode related to ENSO accounts for only a small part of the total variance, the notion of a quasi-linear superposition of forced and unforced modes of variability may not provide an appropriate interpretation of monsoon interannual variability. Consequently, the possibility of a nonlinear influence has been investigated by exploring the relationship between interannual and intraseasonal variability.

As in other studies, a common mode of interannual and intraseasonal variability has been found, in this case describing the north-south transition of the TCZ associated with monsoon active/break cycles. Although seasonal-mean values of the Principal Component (PC) timeseries associated with the leading intraseasonal mode shows no significant correlation with ENSO, the 2-dimensional probability distribution of the PC indices of the two leading modes changes from unimodal in the warm phase of ENSO to bimodal in the cold ENSO phase. These changes are suggestive of some sort of bifurcation in the monsoon properties, with multiple-regime behaviour being established only when the zonal asymmetries in equatorial Pacific SST exceed a threshold value. Although an observational verification of this hypothesis is still to be achieved, the detection of regime-like behaviour in simulations by a complex numerical model gives a stronger support to this dynamical framework than simple qualitative arguments based on the analogy with low-order non-linear systems. 


\section{Introduction}

Understanding the variability of the Asian summer monsoon is one of the most challenging tasks of dynamical climatology. Since the primary cause of the monsoon circulation is the meridional gradient of atmospheric diabatic heating between the Indian Ocean and South Asia, interannual variations in the distribution of diabatic forcing (induced by anomalies in sea surface temperature and land-surface conditions) are important potential sources of monsoon variability. On the other hand, because of dynamical instabilities and physical feedbacks, the monsoon circulation displays a substantial intraseasonal variability which shows quasi-periodic as well as chaotic aspects (see the review by Webster et al. 1998).

The mutual relationship between externally-forced and internal variability of the Asian monsoon is not yet fully understood, and is the subject of current scientific debate. The simplest paradigm to describe such a relationship (which can be traced back to the pioneering work of Charney and Shukla 1981) is to assume a quasi-linear superposition of forced and unforced modes of variability. In this framework, the predictability of forced interannual variations should not be affected by the (possibly chaotic) dynamics of intraseasonal variability; on the other hand, statistics of intraseasonal variability should be relatively insensitive to seasonal-mean anomalies in the large scale flow. A second paradigm, proposed by Palmer (1994) and partially supported by the findings of Ferranti et al. (1997), explains the interannual monsoon variability as a result of changes in the frequency of the preferred flow patterns (or regimes) which characterise the intraseasonal variability. Although such regimes are assumed to be generated by internal non-linear dynamics, their stability properties may be affected by forcing anomalies, with a consequent change in their frequency of occurrence.

Another important issue for the understanding of monsoon variability is the relative importance of sea-surface temperature (SST) and land-surface conditions as sources of anomalous forcing for the large-scale circulation. In the case of SST anomalies, it has been extensively documented that the Asian monsoon responds to the changes in the planetaryscale circulation induced by the El Niño - Southern Oscillation (ENSO) phenomenon (e.g. Webster and Yang 1992; Ju and Slingo 1995). However, the role of SST anomalies in regions adjacent to the Asian continent should not be neglected (see e.g. Soman and Slingo 1998). As far as land surface conditions are concerned, an influence of anomalies in the snow distribution over Asia has long been advocated (starting from Blandford 1884), and has found support in recent modelling studies (e.g. Douville and Royer 1996; Dong and Valdes 1998; Ferranti and Molteni 1999; Bamzai and Marx 2000). The springtime snow distribution, on the other hand, depends on the large-scale circulation anomalies in the preceding winter, raising 
the possibility of indirect links between wintertime ENSO events and monsoon anomalies in the following summer (e.g. Corti et al. 2000; Becker et al. 2001).

Only recently, thanks to the re-analysis projects carried out at the European Centre for Medium-range Weather Forecasts (ECMWF; see Gibson et al. 1997) and at the National Centers for Environmental Predictions (NCEP; see Kalnay et al. 1996), long records of atmospheric data suitable for the study of the interannual variability of the tropical circulation have been made available. Observational studies based on re-analysis datasets, such as that by Sperber et al. (2000), suggest that a plurality of anomalous circulation patterns should be taken into account to describe the various aspects of the interannual variability of the Asian summer monsoon. It was also found that interannual and intraseasonal variability are neither completely decoupled, nor are so strongly related as suggested by Palmer's (1994) simple non linear paradigm (see also Krishnamurthy and Shukla 2000). However, Palmer's hypothesis that the non-linear influence of forcing anomalies on circulation regimes is only manifested in a change of their frequency may be too restrictive, being only appropriate for relatively small forcing perturbations. The consideration of a wider range of non-linear behaviours may lead to other ways of analysing the observational (and modelling) records, reconciling aspects of both linear and non-linear thinking.

Unfortunately, even with using the multi-decadal record provided by NCEP reanalysis, it is difficult to address the dynamical issues outlined above with a high level of statistical significance. Ensemble simulations with atmospheric general circulation models (GCMs), using observed SST as boundary conditions, provide an experimental framework in which the predictability induced by external forcing and the non-linear relationships between forcing anomalies and intraseasonal variability can be effectively investigated.

This paper reports on the effects of SST anomalies on the interannual and intraseasonal variability of the Asian summer monsoon as simulated in a set of ensemble GCM integrations, referred to as the PRISM experiments. These experiments, described in detail in Sec. 2, were originally designed to investigate the relative role of land-surface versus SST anomalies in the monsoon's interannual variability. Preliminary results on this specific issue have already been described in Ferranti and Molteni (1999) and Becker et al. (2001); further diagnostic analyses on the role of land-surface conditions in the full PRISM dataset are under way.

After describing the experimental set-up and the validation datasets in Sec. 2, a comparison between observed and modelled patterns of interannual variability is presented in Sec. 3. In 
Sec. 4, the predictability of interannual variations of the Asian monsoon is addressed using mutually-related patterns of rainfall and $850-\mathrm{hPa}$ wind, defined by means of a singular value decomposition (SVD) of the two fields. The impact of seasonal-mean forcing anomalies on the statistics of intraseasonal rainfall variability is discussed in Sec. 5, and conclusions are drawn in Sec. 6.

\section{Experimental set-up and verification data}

The model simulations analysed in this paper were performed in the context of a numerical experimentation project called PRISM (Predictability experiments for the Indian summer monsoon), which involved scientists from four institutions (CINECA Inter-University Consortium, University of Reading, ECMWF and International Centre for Theoretical Physics). The PRISM experiments consisted of a set of nine 10-member ensemble integrations performed with the ECMWF atmospheric GCM (cycle 16r2; Ritchie et al. 1995), with spectral truncation T63 and 31 vertical levels, using data from the ECMWF re-analysis (ERA; Gibson et al. 1997) as initial and boundary conditions.

The main characteristics of the PRISM ensembles are as follows:

- Each ensemble covered one full year of integration, from the beginning of November to the end of the following October, and was started using a time lagged technique, i.e. with initial conditions separated by 24 hours.

- Simulations for the November-to-March period were run with observed SST, using initial conditions for atmospheric and land-surface variables from ERA (these are referred to as the PRISM-W experiments).

- Model integrations were then restarted, and continued for the April-to-October period using both climatological and observed SST. This experimental configuration makes it possible to compare the effect of anomalies in land-surface conditions only (as produced at the end of the PRISM-W runs) with the combined effect of land-surface and SST anomalies on the summertime circulation. The two sets of summer integrations are referred to as PRISM-C (climatological SST) and PRISM-O (observed SST). 
The years selected for the simulations include the period from $1982 / 83$ to $1988 / 89$, characterised by the alternation of strong warm and cold ENSO events, and two years in the 1990's with quite different SST anomalies and monsoon circulations, namely 1991/92 and 1993/94. The exact initial dates of the ensembles are listed in Table 1.

Table 1. Initial dates of PRISM experiments.

\begin{tabular}{|c|c|c|c|}
\hline & Day & Month & Year \\
\hline PRISM - W & from 1 to 10 & November & $\begin{array}{c}1982,1983,1984,1985,1986,1987, \\
1988,1991,1993\end{array}$ \\
\hline PRISM - C / O & from 1 to 10 & April & $\begin{array}{c}1983,1984,1985,1986,1987,1988, \\
1989,1992,1994\end{array}$ \\
\hline
\end{tabular}

Since this paper investigates the impact of SST anomalies on the statistical properties of interannual and intraseasonal monsoon variability, diagnostics will mostly refer to the PRISM-O experiments. Results from the PRISM-C set will also be discussed, in order to compare the model summertime variability as simulated with and without anomalies in the SST field. A study of the impact of land-surface conditions in the PRISM ensembles will be presented elsewhere. The reader is referred to Ferranti and Molteni (1999) and Becker et al. (2001) for preliminary results on this issue, which were mainly focused on the relationship between snow-depth anomalies and the Asian monsoon circulation.

The statistical properties of the modelled variability have been validated using monthly-mean wind data from the NCEP re-analysis (Kalnay et al. 1996) and monthly-mean rainfall data from the Climate Prediction Center Merged Analysis of Precipitation (CMAP), prepared by Xie and Arkin (1997), for the period 1979-98. Although ERA would appear as the most appropriate reference for the validation of ECMWF model integrations (at least for wind fields), the greater length of the homogeneous record provided by the NCEP datasets increases the significance and robustness of the observed statistics. Also, ERA data are not available to validate the model simulations for summer 1994.

The statistical techniques used to analyse observed and modelled data are widely used in climate research, so that no detailed description is needed here. The empirical orthogonal function/principal component (EOF/PC) analysis used in Sec.3 is described, among many others, by Wilks (1995) and von Storch and Zwiers (1999). EOF analyses of monsoon 
variability on different time scales are found, for example, in Sperber et al. (2000) and Kang et al. (2002). The application of singular value decomposition (SVD) for the analysis of linearly-related patterns in different climatic fields (as in Sec. 4) is discussed in detail by Bretherton et al. (1992). Estimates of probability density functions (PDFs) in a twodimensional space, presented in Sec. 5, are computed using the kernel techniques suggested by Silverman $(1981,1986)$. An excellent discussion on the use of such methods for the analysis of atmospheric variability and flow regimes can be found in Kimoto and Ghil (1993).

\section{Observed and modelled patterns of interannual variability}

Results of the EOF analysis of seasonal (JJAS) means of $850 \mathrm{hPa}$ wind and rainfall from the model ensembles and observational datasets (NCEP reanalysis for wind and CMAP for rainfall) are presented in this section. EOFs were computed in the domain $40^{\circ} \mathrm{N}-20^{\circ} \mathrm{S}, 60^{\circ}-$ $120^{\circ} \mathrm{E}$, as in Annamalai et al. (1999) and Sperber et al. (2000), to describe circulation anomalies over both the Indian subcontinent and South-East Asia.

Before looking at the spatial patterns of the leading EOFs, it is useful to compare the amplitude and distribution of the total variability of observed and modelled anomalies in the domain of investigation. Table 2 shows the rms amplitude of seasonal-mean anomalies averaged over the whole domain, for unfiltered anomalies and for projections on subspaces spanned by the first 3 and 6 EOFs. (No significant meteorological signals were found in the remaining EOFs). The percentages of total variance accounted for by the EOF subspaces are given in parentheses.

Table 2. Root-mean-square amplitude of seasonal-mean anomalies of $850-\mathrm{hPa}$ wind (in $\mathrm{m} / \mathrm{s}$ ) and rainfall (in mm/day) from observations and model ensembles. Percentages of explained variance are given in parentheses.

\begin{tabular}{|c|c|c|c|c|}
\hline & NCEP re-an. & CMAP & PRISM-O & PRISM-C \\
\hline Wind (total) & 0.82 & & 0.99 & 0.80 \\
\hline Wind (EOF 1-6) & $0.71(75.7 \%)$ & & $0.87(77.7 \%)$ & $0.69(74.6 \%)$ \\
\hline Wind (EOF 1-3) & $0.63(58.2 \%)$ & & $0.80(66.4 \%)$ & $0.64(64.6 \%)$ \\
\hline Rainfall (total) & & 1.32 & 2.45 & 1.83 \\
\hline Rainfall (EOF 1-6) & & $1.16(77.4 \%)$ & $1.98(64.8 \%)$ & $1.35(54.1 \%)$ \\
\hline Rainfall (EOF 1-3) & & $1.01(58.4 \%)$ & $1.72(49.4 \%)$ & $1.18(41.9 \%)$ \\
\hline
\end{tabular}


Comparing PRISM-O with observations, it is evident that the ECMWF model tends to overestimate the interannual variability of both wind and rainfall. Looking at the partition of variance among EOF subspaces, the leading EOFs of PRISM-O wind anomalies account for a larger fraction of variance than in observations, while the opposite is true for rainfall. As expected, the variability in the PRISM-O ensembles, which are forced by observed SST, is larger than in the ensembles with climatological SST (PRISM-C).

It may be argued that, since the years of the PRISM experiments were selected for their contrasting ENSO anomalies, the variability in PRISM-O should be larger than in observational datasets which include a number of years with near-normal ENSO indices. However, the fact that the variability in PRISM-C is already as large as (or, for rainfall, larger than) the observed variability suggests that sampling problems cannot be the only cause of the overestimation of variability in PRISM-O experiments. With regard to rainfall data, it should be pointed out that the ratio between the average variability in PRISM-O and CMAP is about 1.7 when estimated from the leading EOF subspaces. This value is very close to the ratio (1.6) between the interannual variability of the all-India rainfall index estimated from ERA and from CMAP data by Annamalai et al. (1999). Since no major changes in convective parametrizations occurred between the two versions of the ECMWF model used in this study and in ERA, it seems plausible that the overestimation of the rainfall variability, detected in PRISM experiments, is mostly caused by deficiencies in convective parameterization which affect the model simulation on both short and long time-scales:

Figure 1 shows the spatial distribution of the rms amplitude of seasonal-mean anomalies projected on the 6-EOF subspace, for observational and model datasets. Contrary to spatiallyaveraged values (Table 2), a better correspondence between the modelled and observed distribution of variability is found for rainfall than for $850-\mathrm{hPa}$ wind. The three areas of large rainfall variability on the windward side of the Western Ghats, on the north-eastern margin of the Bay of Bengal, and just south of the Equator in the eastern Indian Ocean are fairly well reproduced by the model (although with a much stronger amplitude in the Bay of Bengal). Conversely, while the wind variability in the NCEP reanalysis shows a rather uniform distribution between $20^{\circ} \mathrm{N}$ and $10^{\circ} \mathrm{S}$, the model variability shows a marked concentration around $10^{\circ} \mathrm{N}$. Figure 1 also shows that the patterns of variability for PRISM-C are very similar to those of PRISM-O suggesting that interannual SST forcing only amplifies an already existing pattern of variability. This point will be explored in greater depth in the next section. 
The reason for the discrepancy between the observed and simulated wind variability is easily understood by comparing the patterns of the three leading EOFs of $850 \mathrm{hPa}$ wind from NCEP reanalysis and PRISM-O experiments, shown in Fig. 2. The first two wind EOFs from NCEP data in the 1979-98 period, shown in panels (a) and (b), are very similar (apart from arbitrary changes of sign) to the two leading patterns found by Annamalai et al. (1999) for the 1979-94 period. They explain a similar proportion of variance, $26.9 \%$ and $22.1 \%$ respectively. (Note that the EOFs plotted in the figures are scaled by the squared-root of the explained variance, so that they represent the anomaly associated with one standard deviation of the associated PC.)

The first EOF of the observations (Fig 2a) explains $26.9 \%$ of the total variance and is very similar to the first EOF of daily 850 -hPa wind in the same domain, found by Sperber et al. (2000) from the full 40-year record of NCEP reanalysis. It shows a westerly anomaly spanning the whole domain around $15^{\circ} \mathrm{N}$, with an easterly anomaly over the Indian Ocean around the Equator and two centres of cyclonic circulation in the northern part of the Bay of Bengal and over the South China Sea. The ECMWF model reproduces most of these features in the first EOF of PRISM-O (Fig 2d), but with a generally larger amplitude. It also explains a remarkable $51.9 \%$ of the variance in PRISM-O data. However, the axis of the strong westerly anomaly is shifted southwards, around $10^{\circ} \mathrm{N}$, while the intensity of the easterly flow anomaly just south of the Equator is underestimated. The model also fails to capture the along shore wind anomalies off the coast of Sumatra. These have been implicated in the development of the Indian Ocean Dipole or Zonal Mode (e.g. Saji et al. 1999) and suggest that if the model was coupled to the ocean it may have difficulty in reproducing the correct variability in the Indian Ocean.

The second EOF of model data explains a much lower proportion of variance $(7.6 \%)$ than the second NCEP pattern $(22.1 \%)$, and bears little resemblance to it in its spatial structure. Therefore, while in the observations two patterns of comparable amplitude are needed to explain half of the variance in the seasonal mean wind, in the model the wind variability is dominated by just one pattern. A similar result was obtained by Ferranti et al. (1997) using an earlier version of the ECMWF model. On the other hand, a relatively good agreement can be found in the third EOF of observed and model data. This pattern, characterised by an anticyclonic centre south-west of India and a cyclonic centre over the northern part of the Indian sub-continent, resembles the wind pattern associated with positive anomalies of allIndia rainfall found by Sperber et al. (2000). The cyclonic flow over India is stronger in the model than in the reanalysis, but overall the NCEP and PRISM-O patterns have comparable amplitudes and explained variances (9.2\% and $6.9 \%$ respectively). 
EOFs of seasonal mean rainfall from the CMAP 1979-98 dataset and from PRISM-O experiments are shown in Fig. 3. As for the wind EOFs, the first EOF of model data is quite similar to its observed counterpart. In its positive phase, it represents a northward shift of the TCZ in the eastern Indian and western Pacific oceans, with increased rainfall over South-East Asia. The signal over India is relatively weak in both the observed and modelled pattern. However, while in the CMAP EOF it has different signs in the southern and in the northeastern parts of the Indian peninsula, in the PRISM-O EOF the rainfall anomaly over the whole Indian subcontinent has a consistent sign, opposite with respect to the anomaly over South-East Asia. Contrary to the leading EOF of wind data, the first EOF explains the same proportion of variance $(32.5 \%)$ in CMAP and PRISM-O; the larger amplitude of the anomalies in the modelled pattern is therefore a reflection of the overall larger rainfall variability in the model simulations with respect to observations (see Table 2).

The second rainfall EOF also explains similar proportions of variance in the two datasets (13.2\% in CMAP, $10.0 \%$ in PRISM-O); however the spatial patterns are quite different from each other (cf. fig. $3 b$ and $3 e$ ). The second EOF of PRISM-O, with three regions of alternating signs in the north-south direction between $80^{\circ} \mathrm{E}$ and $100^{\circ} \mathrm{E}$, is actually more similar to the third CMAP EOF. In both the first and the second EOF, the model has failed to capture any of the observed variability over China. The third EOF of PRISM-O (in Fig. 3f), although explaining only $6.9 \%$ of the variance, is quite relevant to the representation of rainfall anomalies over India, and may be interpreted as a shift of the TCZ between the Indian subcontinent and the central part of the Indian Ocean.

The poor simulation of the pattern of variability over the West Pacific and Maritime Continent, where the model behaviour appears to be dominated by a local Hadley circulation, may also have implications for the model's response to ENSO. Slingo and Annamalai (2001) have emphasised the importance of the balance between the modulation of the Walker and the local Hadley circulations in the region of the Maritime Continent for determining the observed response of the Asian Summer Monsoon to ENSO.

Although the relationship between $850-\mathrm{hPa}$ wind and rainfall anomalies in the model simulations will be properly addressed in the next section, it may be anticipated that a strong correlation (97\%) exists between the principal components (PCs) associated to the first wind EOF and to the first rainfall EOF of the PRISM-O simulation. Therefore, these two patterns (shown in Fig. 2d and Fig. 3d respectively) describe the dominant mode of interannual variability of the Asian summer monsoon in the ECMWF model. A similar pattern of 
variability was identified by Ferranti et al. (1997) as the leading mode of both intraseasonal and interannual monsoon variability in simulations made with an earlier version of the ECMWF model. It is therefore interesting to investigate to what extent such a mode is present in the PRISM-C simulations, in which no SST anomalies are present during the summer months, and internal dynamics is expected to play a proportionally larger role than in PRISM$\mathrm{O}$ experiments in determining the seasonal-mean anomalies.

The first EOF of 850-hPa wind and rainfall from the PRISM-C experiments are shown in Fig. $4 \mathrm{a}$ and $4 \mathrm{~b}$ respectively. Comparing these anomaly patterns with those in Fig. $2 \mathrm{~d}$ and Fig. $3 \mathrm{~d}$ respectively, one can see that essentially the same dominant mode is simulated even in the absence of SST anomalies. The percentages of variance explained by the leading EOF in PRISM-C (53.0\% for wind, $28.8 \%$ for rainfall) are also very similar to the corresponding values for PRISM-O ensembles. This is a further indication that the dominant mode of interannual variability in the model is an internal mode of the atmosphere whose amplitude but not its structure may be modified by SST forcing. This point will be developed further in the next section.

In conclusion, the seasonal-mean variability simulated by the ECMWF model has undoubtedly a number of common features with the observed variability, but important discrepancies are also present. In particular, the variance of the lower tropospheric winds appears to be dominated by one mode, instead of being more evenly distributed among alternative patterns. The dominance of this zonally-oriented mode in the ECMWF model is also a common feature of other models studied by Sperber et al. (2001).

\section{Predictability of interannual variations described by SVD patterns}

Singular value decomposition (SVD) of the cross-covariance matrix of two multi-variate datasets represents an efficient and widely used method for the analysis of the relationship between meteorological variables (Bretherton et al. 1992). In many studies using this technique, SVD is not applied directly to original data defined over stations or grid points in physical space, but rather to projections on suitable subspaces spanned by the leading EOFs of the two fields. In this way, when non-standardised PCs are used as input variables, SVD defines an orthogonal rotation for each of the original EOF subspaces, such that the crosscovariance matrix of the rotated time coefficients is reduced to a diagonal matrix. 
Here, SVD analysis was used to define two sets of orthogonal patterns which account for most of the cross-covariance between $850-\mathrm{hPa}$ wind and rainfall anomalies in the seasonal (JJAS) means simulated in the PRISM-O experiments. Non-standardised PCs associated to the first six EOFs of each field were used as input variables. This particular truncation of the EOF subspace was chosen on the basis of two criteria: the large fraction of variance explained by the subspace ( $78 \%$ for wind, $65 \%$ for rainfall: see Table 2 ), and the absence of significant meteorological signals in the neglected EOFs (none of which explained more than $3 \%$ of the total variance).

The leading two SVD patterns of $850-\mathrm{hPa}$ wind and rainfall anomalies in PRISM-O (defined by the left and right singular vectors of the cross-covariance matrix) are shown in Fig. 5. As for the EOFs displayed in Figs. 2 and 3, the patterns are scaled to represent the anomalies corresponding to one standard deviation of the associated time coefficient (i.e. the rotated PC). The correlation between the wind and rainfall coefficients of the first SVD mode is $95 \%$; the same percentage is obtained for the second mode (note that SVD modes are ordered according to cross-covariance, not correlation). In the following, the analysis will be focused on just these two SVD modes, since they represent those patterns of model variability for which an observational counterpart can be clearly identified.

The structure of the first SVD mode (Fig. 5a, 5d) bears a very strong similarity to the pattern of the first EOF of the two fields. This is hardly surprising, given the very strong correlation between the first wind and rainfall PC, anticipated in the previous section. A widespread westerly anomaly of $850-\mathrm{hPa}$ wind in a latitudinal belt centred at $10^{\circ} \mathrm{N}$ is associated with a northward position of the TCZ over the Bay of Bengal and South-East Asia. With the sign shown in the figure, the SVD wind pattern corresponds to a positive value of the dynamical monsoon index (DMI) defined by Webster and Yang (1992) based on zonal-wind anomalies. Although observed values of the DMI are found to be positively correlated with the all-India rainfall (AIR), there is no strict correspondence between these two monsoon indices. In particular, as shown in Ju and Slingo (1995), opposite values of the two indices were observed in many years during the 1980's (which are included in the PRISM sample). Given the negative rainfall anomaly present over India in the rainfall component of the first SVD mode, the contribution of such a mode to the (modelled) correlation between DMI and AIR is actually of negative sign.

The second SVD mode (Fig. 5b, 5e) describes a relationship between a wind anomaly very similar to the third wind EOF (cf. Fig. 2f) and a rainfall pattern looking like a linear superposition of the second and third rainfall EOFs (Fig. 3 e-f). A cyclonic wind anomaly is 
associated with positive rainfall anomalies over the Indian subcontinent, while negative rainfall anomalies cover most of the Indian Ocean around the Equator. The wind-rainfall relationship described by this mode is fairly consistent with the composite analysis of the same variables based on seasonal means of AIR, reported in the observational study by Sperber et al. (2000). In the PRISM-O simulations, the rotated PC representing the rainfall component of this SVD mode has a correlation of $50 \%$ with an AIR index defined as the mean rainfall anomaly on all land points over India, where the topographic height is less than $1 \mathrm{Km}$.

The SVD analysis of $850-\mathrm{hPa}$ wind and rainfall was also performed on seasonal-mean anomalies from the PRISM-C experiments, in order to ascertain whether the patterns of the leading SVD modes could be reproduced in the absence of anomalous SST forcing. As for PRISM-O experiments, the wind and rainfall components of the first SVD mode are almost identical to the first EOF of the respective fields (shown in Fig. $4 \mathrm{a}, \mathrm{b}$ ). It was noted above that the first EOF of PRISM-O and PRISM-C experiments are very similar to each other, for both wind and rainfall. Consistently, a close similarity is also found for the first SVD mode (not shown), suggesting that this mode of variability is mainly associated with internal atmospheric dynamics. On the other hand, the second SVD mode of PRISM-C (shown in Fig. $5 c$ and 5f) resembles the corresponding PRISM-O mode only in the region of the Indian subcontinent, but shows no significant features over the Indian Ocean. A possible interpretation is that, in the absence of anomalous SST forcing, the rainfall variability over India associated with regional cyclonic/anticyclonic flow remains "decoupled" from largerscale anomalies in the equatorial belt, while a stronger link between the two regions is induced by SST anomalies.

In order to quantify the influence of SST on the modes of variability represented by the first two SVD patterns of PRISM-O, correlations between ensemble-mean values of the rotated PCs of JJAS wind and SST anomalies in different months (before and during the summer season of each year) are shown in Figs. 6 and 7. Note that all the simulations in the ensemble for a given year have the same SST, therefore these correlations are determined by only nine independent values, and have a poor statistical significance.

For the first SVD mode, the correlations with SST (Fig. 6) show a rather weak signal. Since the positive phase of this mode is associated with positive values of Webster and Yang's (1992) DMI, a negative correlation with SST anomalies in the eastern equatorial Pacific would be consistent with the observed correlation between DMI and ENSO. Instead, the correlation pattern in the eastern Pacific is hardly significant, turning from weakly negative in 
the preceding winter to positive in late summer. A stronger signal is present in the Indian Ocean and the western Pacific during winter, but it gets progressively weaker with time. Overall, there is no evidence of a significant influence of SST on the first SVD mode of monsoon variability in the PRISM-O experiments.

For the second SVD mode, which has a strong projection on to Indian rainfall, the relationship with SST is much stronger (see Fig. 7). A pattern characteristic of decaying ENSO, with negative correlations along the equator in both the eastern Pacific and the Indian Ocean, is present in the preceding winter and spring. During summer, the negative correlations with East Pacific anomalies tend to decrease, while those in the Indian Ocean get stronger, consistent with the well documented lagged response of the Indian Ocean to ENSO. The strong negative correlations over the northern Indian Ocean during summer imply a change in the meridional temperature gradient with cooler SSTs acting to predispose the monsoon to an active land TCZ. These results suggest that the Indian Ocean may play an important role in the variability of the Indian Summer Monsoon, at least in the model, and that the influence of ENSO on the monsoon may be via the Indian Ocean. Recent results by Spencer et al. (2002) support the notion that the lagged response of the Indian Ocean to ENSO forcing may have a significant impact on the global teleconnections particularly over the Asian Summer monsoon domain.

The predictability of the anomalies represented by the PRISM-O SVD modes in Fig. 5 is addressed in Fig. 8, which shows the time series of the rotated PCs associated with the two modes, for both $850-\mathrm{hPa}$ wind and rainfall. Values corresponding to individual experiments in the PRISM-O ensembles, as well as ensemble-mean values, are shown in the four panels. The PC values are compared with the projections of observed anomalies (computed from NCEP reanalysis and CMAP data) on the same SVD patterns for the period 1979-98. (To make the comparison easier, the observed projections are actually re-normalised by a factor equal to the average ratio between modelled and observed variability, as deduced by the r.m.s. amplitude of anomalies in the 6-EOF subspace listed in Table 2.)

Comparing the time series of the two modes, it is found that the ratio of ensemble-mean variability to the internal variability within the ensembles is larger for the second SVD mode than for the first one. (The ratios of ensemble mean variance to internal variance are listed in Table 3). This is particularly evident during the La Niña years of the mid-1980's (e.g. 1984 and 1985). However, even more evident is the difference in the correlation between ensemble-mean and observed projections on the two SVD patterns. While for the first SVD mode the correlation is insignificant ( $15 \%$ for wind data, $12 \%$ for rainfall), for the second 
SVD mode these coefficients rise to $78 \%$ for wind and to $96 \%$ for rainfall. These findings are fully consistent with the correlations between rotated PCs and SST discussed above: the ensemble-mean variability of the second SVD mode has an opposite phase with respect to the El Niño cycle.

Table 3 - Ratio between ensemble-mean variance end ensemble variance for the two leading SVD modes of the PRISM-O experiment.

\begin{tabular}{|c|c|c|}
\hline & WIND PRISM-O & RAINFALL PRISM-O \\
\hline SVD1 & 0.81 & 1.53 \\
\hline SVD2 & 2.78 & 2.54 \\
\hline
\end{tabular}

The influence of SST forcing on the predictability of the SVD modes is made evident in Fig. 9, which shows similar graphs to Fig. 8 , but where projections of model anomalies from PRISM-C onto the PRISM-O SVD patterns are used instead of PRISM-O projections. The absence of SST anomalies in the PRISM-C experiments notably reduces the variability of ensemble-mean values with respect to PRISM-O data, and the positive correlations with observed anomalies disappear for the second SVD mode.

In summary, this section has provided a picture of monsoon variability in the ECMWF model simulations which has one important aspect in common with the observational findings of Sperber et al. (2000): namely, the mode of variability which is most strongly related to ENSO is not the mode which accounts for the largest proportion of variance. The leading mode of interannual variability identified by the SVD analysis is not influenced significantly by SST forcing, according to the statistics discussed above. This suggests that the paradigm proposed by Charney and Shukla (1981) of a quasi-linear superposition of forced and unforced modes of variability acting on different time scales may not provide an exhaustive interpretation of monsoon interannual variability. However, the possibility of a non-linear influence has still to be investigated in the context of the relationship between interannual and intraseasonal variability and this will form the focus of the next section.

\section{Impact of SST anomalies on intraseasonal variability}

A lot of the scientific debate on the relationship between intraseasonal and interannual variability of the Asian monsoon can be summarised by the following questions: 
1) Are there common patterns of variability between the two time scales?

2) Is it possible to represent interannual variations as the result of changes in the probability distribution of the common modes of variability?

3) Does the probability density function (PDF) of indices of intraseasonal monsoon variability display features which are indicative of non-linear regime behaviour, and is the frequency of occurrence of such regimes affected by interannual variations in surface conditions?

A negative answer to all three questions would imply a total decoupling between intraseasonal and interannual variability. However, few studies are supportive of such an extreme position. Some recent works (e.g. Krishnamurthy and Shukla 2000; Sperber et al. 2000) have shown that some common modes may exist, but the influence of boundary forcing on the distribution of such modes can be simply described by a shift in the time mean, with no evidence of non-linear and regime-like behaviour. . On the other hand, other observational studies (e.g. Goswami and Ajaya Mohan 2001) advocate a stronger role for intraseasonal oscillations in determining the seasonal-mean variability of the monsoon.

It should be pointed out that trying to answer question (3) just on the basis of the observed record is extremely difficult. If one is concerned with indices of variability over the whole region affected by the Asian monsoon, then the length of the available data is limited to a few decades, and the statistical significance of multimodality in PDF of such indices is hard to prove. In addition, to address question (3) the observed sample has to be stratified according to the prevailing boundary conditions, so that detecting a significant difference in the PDFs for, say, El Niño vs. La Niña conditions may become even more elusive. So, perhaps the only viable strategy to answer question (3) is to look for regime behaviour in ensembles of GCM simulations, where the response to specific boundary conditions can be replicated many times, and then verify whether the results are consistent with observed signals whose statistical significance cannot be proven at a high confidence level.

The PRISM-O ensembles, which simulate years with large ENSO variability, are well suited to this kind of investigation. The first step, i.e. the detection of possible common modes of variability between intraseasonal and interannual variability, was performed through an EOF analysis of 5-day-mean (pentad) rainfall on the same geographical domain used for the analysis of seasonal means. Pentad rainfall anomalies were defined with respect to a moving 25-day-mean climatology, centred on each pentad and including data from all PRISM-O experiments. The time domain of this analysis again covers the June-to-September season, 
but with the exclusion of the first two pentads of June and the last two of September in order to have a more homogeneous sample in terms of rainfall variability.

The EOF analysis was performed first on the "total" pentad anomalies, then on intraseasonal anomalies, i.e. on the departures of pentad anomalies from the seasonal-mean anomaly of each experiment. Similarly to what shown for interannual variations (see Fig.1 d-e) Fig. 10 compares the rms amplitude of observed and modelled pentad anomalies projected on the first 6 EOFs (for this purpose the 5-day mean version of the CMAP dataset was used, as in Sperber et al. 2000). As for the interannual timescale, an overestimation of modelled rainfall variability is particularly evident on the eastern side of the Bay of Bengal, while rainfall variations over most of the Indian peninsula are smaller than observed.

The first two EOFs of pentad rainfall are shown in Fig. 11; EOFs of "total" anomalies are shown in the left column (panels $a-b$ ), those of intraseasonal anomalies in the right column (panels c-d). It is evident that the subtraction of seasonal means has little effect on the EOF patterns: the spatial correlation between the "total" and intraseasonal EOF with the same rank is 0.96 for EOF-1, 0.97 for EOF-2. The fractions of explained variance reflect the stronger contributions of EOF-1 to the interannual variability: for EOF-1, the percentage decreases from $11.1 \%$ to $7.5 \%$ when seasonal-means are removed, while it stays almost constant for EOF-2 (6.5\% vs. $6.6 \%)$.

These patterns can be also compared with the leading rainfall EOFs of seasonal-mean anomalies in Fig. 3 (d-f) and with the rainfall components of the two interannual SVD modes in Fig. 5 (d-e). Notably, the first intraseasonal EOF is almost identical to the leading mode of interannual rainfall variability. The similarity of the dominant modes of interannual and intraseasonal variability, both characterised by a zonally oriented pattern of anomalies, was also found by Ferranti et al. (1997) in an earlier version of the ECMWF models and appears to be a feature of other models (Sperber et al. 2001). The second intraseasonal EOF resembles the third EOF of seasonal-mean rainfall, and is also positively correlated with the second SVD mode, although with a stronger centre of variability on the northern edge of the Bay of Bengal.

In order to quantify the correspondence between the leading subspaces of intraseasonal and interannual variability in PRISM-O ensembles, the seasonal-mean anomaly of each experiment (defined as the average anomaly in the period covered by the pentad rainfall analysis) was projected on the two subspaces spanned respectively by the first two EOFs of intraseasonal anomalies and by the rainfall components of the two leading interannual SVD 
modes. For each of the 90 anomalies from the ensemble members, the spatial correlation between the two projections was computed: the distribution of such coefficients is shown by the histogram in Fig. 12. In the majority of cases, the correlation coefficient exceeds 0.8 , with only 22 out of 90 experiments showing a lower correlation than 0.7 . For ensemble-mean anomalies, correlation coefficients greater than 0.7 were obtained in 7 out of 9 cases.

From these results, the existence of common modes of variability between the intraseasonal and interannual scale is clearly manifested in the PRISM-O ensembles, these mode being the dominant ones on both time scales. Therefore, the EOFs and PCs of "total" pentad anomalies provide an effective representation of rainfall variability on both scales, and can be used to investigate the influence of anomalous boundary forcing on the probability distribution of monsoon rainfall.

In order to address this issue, bi-dimensional probability density functions (PDFs) of the two leading PCs of pentad rainfall were computed using an iterative gaussian kernel estimator in which the width $h$ of the kernel function is defined as a fraction of the standard deviation of the original time series (Silverman 1981, 1986). In particular, we are interested in the possible existence of multimodality in the PDF, since this maybe indicative of the presence of multiple quasi-stationary flow patterns (regimes) in the model climate. (For further explanations and examples on this issue see the papers by Hansen and Sutera 1986, Kimoto and Ghil 1993, Palmer 1994, Ferranti et al. 1997, Corti et al. 1999, and the review article by Molteni 2003.)

As discussed in Silverman (1981), for a given data record, the number of modes (i.e. local maxima) in the estimated PDF is a monotonically decreasing function of the width of the gaussian kernel. This property allows a simple yet rigorous test of the significance of multimodality in the estimated PDF. If a PDF is computed with increasing values of the kernel width (i.e. with increasing smoothing), one can estimate the largest value of $h$ for which the PDF is multimodal. Such a value can then be used to estimate the PDF of a large number of random samples, of the same size as the original record, extracted from a population with unimodal distribution and the same mean, variance and lag-1 autocorrelation of the original data. The proportion of multimodal distributions obtained (simply because of random sampling) from the red-noise samples is an inverse measure of the statistical significance of multimodality in the original sample.

The bi-dimensional PDF of (PC-1, PC-2), estimated with $h=0.30$, is shown in Fig. 13a for the full record of 5-day-mean rainfall in the 90 PRISM-O simulations. The PDF is non- 
isotropic, with an absolute maximum corresponding to negative values of both PCs (i.e. of weak monsoon conditions according to the chosen sign of the EOFs), and shows a weak secondary maximum close to the origin of the axes. The PDF remains bimodal until a kernel width of $h=0.35$ is exceeded; the random-noise test indicates that the probability of bimodality being due to random sampling is $12.2 \%$ with such a threshold.

To investigate the influence of ENSO on PC statistics, the data sample was divided in two parts according to the seasonal (JJAS) mean value of the bivariate ENSO index defined by Smith and Sardeshmukh $(2000)^{3}$. Of the nine summers covered by PRISM-O ensembles, four $(1984,1985,1988,1989)$ have negative seasonal-mean indices with respect to a multidecadal mean, corresponding to cold events in the eastern tropical Pacific, while the other five summers are representative of warm events. The PDFs obtained from the two subsamples of cold and warm ENSO summers (estimated with $h=0.35$ to compensate for the reduced sample size) are shown in Fig. $13 \mathrm{~b}$ and $13 \mathrm{c}$ respectively.

The partition according to the ENSO phase shows that bimodality in the PDF is only present in the cold phase, when two regimes can be easily identified, while in the warm phase the PDF is skewed but unimodal. The difference between PDFs in warm and cold ENSO, shown in Fig. 13d, indicates that warm events increase the frequency of states close to weakmonsoon PDF maximum. Conversely, phase-space regions with moderately positive values of PC1 and PC2 become more populated during cold events, when a second mode is established.

Neither a simple shift in the mean state, nor a change of frequency between two ever-present regimes, seems the most appropriate description for the PDF changes between warm and cold ENSO events. Rather, these changes are suggestive of some sort of bifurcation in the monsoon properties, with a multiple-regime behaviour being established only when the zonal asymmetries in equatorial Pacific SST exceed a threshold value. Molteni and Corti (1998) noted a similar behaviour in quasi-geostrophic simulations of North-Pacific large-scale anomalies, again finding that a forcing pattern corresponding to warm ENSO conditions induced unimodality in an otherwise bimodal PDF. The emergence of bi-modality in certain

\footnotetext{
${ }^{3}$ The seasonal means of the bivar. ENSO index were obtained by averaging the JJAS monthly values of the time-series published at the NOAA-CIRES website: http://www.cdc.noaa.gov/ cas/best/\#years. In some years, the JJAS averages do not have the same sign as the winter averages listed in Table 1 of Smith and Sardeshmukh (2000).
} 
years was also noted in Ferranti et al. (1997), but in their case only when the intraseasonal mode was particularly active.

In such a situation, it is perhaps more appropriate to test the significance of the bimodality in the cold-ENSO PDF, rather than in the PDF of the full sample. The smaller size of the subsample ( 40 versus 90 simulations) is bound to reduce the confidence for the same value of the smoothing parameter. However, the cold-ENSO PDF is still bimodal when estimated with $h=0.40$ (not shown), when only $8.6 \%$ of red-noise PDFs appear to be multimodal.

Although it is better revealed by bi-dimensional estimates, the transition from unimodal to bimodal distribution in opposite ENSO phases is also detectable in one-dimensional PDF estimates for the first PC only, shown in Fig. 13e. In one dimension, multimodality can be significantly detected for smaller values of $h$ than in 2-D estimates, therefore a value of $h=$ 0.25 was used here. In this case, the chance of "spurious" bimodality in the cold-ENSO subsample, estimated from red-noise data, is as low as $4.4 \%$, with a level of significance exceeding $95 \%$.

It should be stressed that these model results do not guarantee the existence of regimes in the observed monsoon circulation. As mentioned above, the detection of regime behaviour is rather difficult from observational records, because of longer timescale changes in the forcing and because of the presence of interdecadal trends in the monsoon circulation given in the NCEP reanalyses. For example, Sperber et al. (2000) found that the dominant mode of interannual variability in the winds from the NCEP Reanalyses represented the decadal timescale weakening of the monsoon circulation associated with the warming of the Indian Ocean over the last 40 years. However, the PRISM-O results do show that regime behaviour is not only a feature of low-order dynamical models, although a simple "extrapolation" of the behaviour of such models may be inappropriate. As a consequence, significance tests applied to observed data should reflect the "dynamical plausibility" of the regime hypothesis, when compared with standard null hypotheses derived from purely statistical reasoning.

\section{Summary and conclusions}

The effects of SST anomalies on the interannual and intraseasonal variability of the Asian summer monsoon have been investigated by multivariate statistical analyses of 850 -hPa wind and rainfall fields from a set of ensemble simulations performed with the ECMWF atmospheric GCM, referred to as the PRISM experiments. In particular, analyses have 
focused on simulations of the northern summer circulation over south Asia using observed SST (PRISM-O experiments), which covered 9 years characterised by large variations of the ENSO phenomenon in the 1980's and the early 1990's.

The main results of our analyses can be summarised as follows.

- The dominant mode of interannual variability of the Asian summer monsoon, as simulated by the ECMWF model, consists of a zonally-coherent anomaly of $850-\mathrm{hPa}$ wind centred at $10^{\circ} \mathrm{N}$, associated with a meridional shift of the TCZ from the equatorial Indian Ocean to the Bay of Bengal and South-East Asia. Although a similar variability pattern is found in observational data, the ECMWF model overestimates the fraction of variance explained by this mode, particularly of its wind component.

- The second mode of variability emerging from the SVD analyses of wind and rainfall fields also has a good correspondence with observed patterns of variability. In its positive phase, a cyclonic wind anomaly is associated with positive rainfall anomalies over the Indian subcontinent, while negative rainfall anomalies prevail over the Indian Ocean near the equator.

- While the association between the first SVD mode and SST anomalies is rather weak, leading to a poor predictability of its interannual variability, the second mode shows a clear relationship to the ENSO cycle. As a consequence, the interannual variations of the amplitude of SVD-2 anomalies are successfully simulated by the ensemble means, with a correlation of $96 \%$ between modelled and observed values of the associated rainfall index.

- An EOF analysis of 5-day-mean rainfall from PRISM-O ensembles revealed a strong similarity between the dominant patterns of rainfall variability on the interannual and intraseasonal scale. Although seasonal-mean values of the PC associated with the leading rainfall pattern shows no significant correlation with the ENSO index, the 2-dimensional probability distribution of the leading 5-day-mean PC indices is turned from unimodal in the warm phase of ENSO to bimodal in the cold ENSO phase.

These findings contain a mixture of good and bad news as far as the prospects for numerical seasonal predictions of the Asian monsoon are concerned. On the one hand, the high correlation coefficients between observed and simulated (ensemble-mean) values of the 
SVD-2 index, which is related to the All-India Rainfall index, represent a notable and encouraging result. On the other hand, consistent with the observational study of Sperber et al. (2000), the PRISM-O simulations indicate that the mode of monsoon variability most strongly related to ENSO is not the one which accounts for the largest proportion of variance. Additionally, it should be noted that our numerical simulations of monsoon variability patterns were affected by significant discrepancies from observations in the partition of variance between modes with different regional characteristics.

With regard to a theoretical understanding of monsoon dynamics, and particularly of the impact of boundary forcing on the statistics of intraseasonal variability, PRISM results highlight the limitations of the simple paradigms proposed so far for the interpretation of such a relationship. As stated above, neither a simple shift in the mean state, nor a change of frequency between two ever-present regimes, is an appropriate description for the PDF changes between warm and cold ENSO events in PRISM-O simulations. The change in the PDF from unimodal to bimodal according to the ENSO phase is rather suggestive of some type of bifurcation process, such as those encountered in the study of many non-linear dynamical systems when forcing parameters are changed in a continuous way.

On the basis of this study, we cannot state whether the PRISM-O results on this issue are confirmed by observations. However, the detection of regime-like behaviour in the monsoon simulations by a complex numerical model gives a stronger appeal to this dynamical framework than simple qualitative arguments based on the analogy with low-order non-linear systems.

\section{Acknowledgements:}

The authors are grateful to an anonymous referee for his constructive suggestions. The PRISM experiments were performed with computing time provided through an ECMWF Special Project. Julia Slingo acknowledges the support of the NERC UK Universities' Global Atmospheric Modelling Programme (UGAMP). 


\section{References}

Annamalai, H., J.M. Slingo, K.R. Sperber and K. Hodges, 1999: The mean evolution and variability of the Asian summer monsoon: Comparison of ECMWF and NCEP/NCAR Reanalyses. Mon. Wea. Rev., 127, 1157-1186.

Bamzai, A.S., and L. Marx, 2000: COLA AGCM simulations of the effect of anomalous spring snow cover over Eurasia on the Indian summer monsoon. Q.J.R.Meteorol.Soc., 126, 2575-2584.

Becker, B.D., J.M. Slingo, L. Ferranti and F. Molteni, 2001: Seasonal predictability of the Indian summer monsoon: What role do land-surface conditions play? Mausam, 52, Special Issue on Climate Change, 175-190.

Blandford H. F. 1884: On the connection of the Himalaya snowfall with dry winds and seasons of drought in India. Proc. Roy. Soc., 37, 3-22

Bretherton C S, C Smith and J M Wallace 1992: An intercomparison of methods for finding coupled patterns in climate data. J.Climate, 5, 541-560.

Charney J.G. and J. Shukla, 1981: Predictability of monsoon. In "Monsoon Dynamics", Cambridge University Press, pp 99-110.

Corti, S., F. Molteni and C. Brankovic, 2000: Predictability of snow-depth anomalies over Eurasia and associated circulation patterns. Q.J.R.Meteorol.Soc., 126, 241-262.

Corti, S., F. Molteni and T.N. Palmer, 1999: Signature of recent climate change in frequencies of natural atmospheric circulation regimes. Nature, 398, 799-802.

Douville H., and J.-F. Royer, 1996: Sensitivity of the Asian summer monsoon to an anomalous Eurasian snow cover within the Meteo-France GCM. Climate Dynamics $12,449-466$

Dong, B. and P.J. Valdes, 1998: Modelling the Asian summer monsoon rainfall and Eurasian winter/spring snow mass. Q.J.R.Meteorol.Soc., 124, 2567-2596.

Ferranti L. and F. Molteni, 1999: Ensemble simulations of Eurasian snow-depth anomalies and their influence on the Asian summer monsoon. Q. J. R. Meteorol. Soc., 125, 2597-2610.

Ferranti L., J. M. Slingo, T. N. Palmer and B. J. Hoskins, 1997: Relations between interannual and intraseasonal monsoon variability as diagnosed from AMIP integrations. Q. J. R. Meteorol. .Soc. 123, 1323-1357

Gibson, J. K., P. Kallberg, S. Uppala, A. Hernandez, A. Nomura, E. Serrano, 1997: ERA description. ECMWF Re-Analysis Project Report No. 1. 
Goswami, B.N. and R.S. Ajaya Mohan, 2001: Intra-seasonal oscillations and inter-annual variability of the Indian summer monsoon. J. Climate, 14, 1180-1198.

Hansen, A.R. and A. Sutera, 1986: On the probability density distribution of large-scale atmospheric wave amplitude. J. Atmos.Sci, 43, 3250-3265.

Ju, J. and J. M. Slingo, 1995: The Asian monsoon and ENSO. Q. J. R. Meteorol. Soc., 121, 1133- 1168.

Kalnay E., M. Kanamitsu, R. Kistler, W. Collins, D. Deaven, L. Gandin, M. Iredell, S. Saha, G. White, J. Woollen, Y. Zhu, M. Chelliah, W. Ebisuzaki, W.Higgins, J. Janowiak, K. C. Mo, C. Ropelewski, J. Wang, A. Leetmaa, R. Reynolds, R. Jenne, and D. Joseph, 1996: The NCEP/NCAR 40-Year Reanalysis Project. Bull. Am. Meteorol. Soc., $77,437-471$.

Kang, I.-S., K. Jin, B. Wang, K.-M. Lau, J. Shukla, V. Krishnamurthy, S.D. Schubert, D.E. Wailser, W.F. Stern, A. Kitoh, G.A. Meehl, M. Kanamitsu, V.Y. Galin, V. Satyan, C.-K. Park, and Y. Liu, 1993: Intercomparison of the climatological variations of Asian summer monsoon precipitation simulated by 10 GCMs. Climate Dyn., 19, 383395.

Kimoto, M. and M. Ghil, 1993: Multiple flow regimes in the northern hemisphere winter: Part I: Methodology and Hemispheric regimes. J.Atmos.Sci, 50, 2625-2643.

Krishnamurthy, V. and B. N. Goswami, 2000: Indian Monsoon-ENSO relationship on interdecadal timescale. J. Climate, 13, 579-595.

Krishnamurthy, V. and J. Shukla, 2000: Intraseasonal and interannual variability of rainfall over India. J. Climate, 13, 4366-4377.

Kumar, K.K., B. Rajagopalan and M.A. Cane, 1999: On the weakening relationship between the Indian monsoon and ENSO. Science, 284, 2156-2159.

Molteni, F. 2003: Weather regimes and multiple equilibria. In: Encyclopaedia of Atmospheric Sciences, Academic Press, 2577-2586.

Molteni, F. and S. Corti, 1998: Long-term fluctuations of the statistical properties of lowfrequency variability: Dynamical origin and predictability. Q.J.R.Meteorol.Soc., 124, 495-526.

Palmer, T.N., 1994: Chaos and predictability in forecasting the monsoon. Proc. Indian Nat. Sci. Acad. 60 No.1, 57,66.

Parthasarathy, B. A.A. Munot, and D.R. Kothawale, 1994: All-India monthly and seasonal rainfall series: 1871-1993. Theor. Appl. Climatology, 49, 217-224.

Ritchie H., C. Temperton, A. Simmons, M. Hortal, T. Davies, D. Dent and M. Hamrud 1995: Implementation of the semi-Lagrangian method in a high-resolution version of the ECMWF forecast model. Mon. Wea. Rev. 123, 490-514. 
Saji N. .H, B. N. Goswami, P. N. Vinayachandran and T. Yamagata 1999: A dipole mode in the tropical Indian Ocean. Nature, 401, 360-363

Silverman, B .W., 1981: Using kernel-density estimators to investigate multimodality. J.Roy.Stat.Soc., B43, 97-99.

Silverman, B .W., 1986: Density estimation for statistics and data analysis. Chapman and Hall, New York.

Smith, C.A. and P. Sardeshmukh, 2000: The effect of ENSO on the intraseasonal variance of surface temperature in winter. Int. J. Climatology, 20, 1543-1557.

Soman M. K. and J. M. Slingo, 1997: Sensitivity of Asian summer monsoon to aspects of sea surface temperature anomalies in the tropical Pacific Ocean. Q. J. R. Meteorol. Soc. $123,309-336$

Spencer, H., J. M. Slingo, and M. Davey, 2002: The influence of remote SST anomalies on the long range predictability of ENSO teleconnections. submitted to J. Climate

Sperber K.R., J.M. Slingo,. and H. Annamalai, 2000: Predictability and the relationship between subseasonal and interannual variability during the Asian summer monsoon. Q. J. R. Meteorol. Soc., 126, 2545-2574.

Sperber, K. R., C. Brankovic, M. Deque, C. S. Frederiksen, R. Graham, A. Kitoh, C. Kobayashi, T. N. Palmer, K. Puri, W. Tennent, and E. Volodin, 2001: Dynamical Seasonal Predictability of the Asian Summer Monsoon. Mon. Wea. Rev., 129, 22262248.

Von Storch, H. and F.W. Zwiers, 1999: Statistical analysis in climate research. Cambridge University Press, 484 pp.

Webster, P.J, V. O. Magana, T. N. Palmer, J. Shukla, R. A. Tomas, M. Yanai and T. Yasunari 1998: Monsoons: Processes, predictability, and prospects for prediction. J. Geophys. Res. 103, 14451-14510.

Webster, P.J. and S. Yang, 1992: Monsoon and ENSO: Selectively interactive systems. Q. J. R. Meteorol. Soc., 118, 877-926.

Wilks D. S., 1995: Statistical methods in the atmospheric sciences. Academic Press, San Diego, 465pp.

Xie P. and P Arkin, 1997: Global precipitation: A 17-year monthly analysis based on gauge observations, satellite estimates and numerical model outputs. Bull. Amer. Meteorol. Soc., 78, 2539-2558. 
(a) RMS [EOFs 1-6] wind $850 \mathrm{hPa}$ NCEP RA

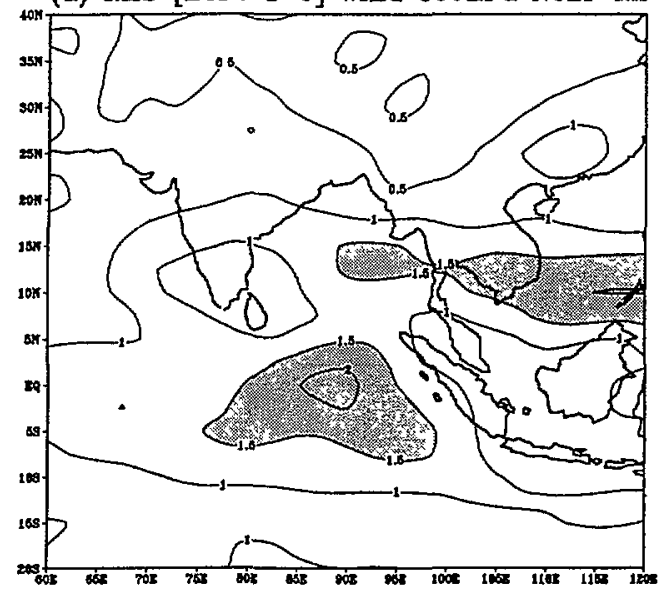

(b) RMS [EOFs 1-6] wind $850 \mathrm{hPa}$ PRISM-0

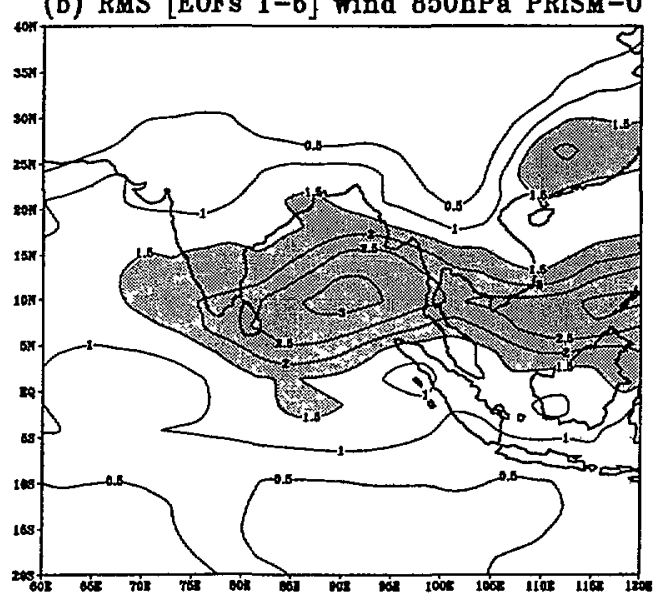

(c) RMS [EOFs 1-6] wind $850 \mathrm{hPa}$ PRISM-C

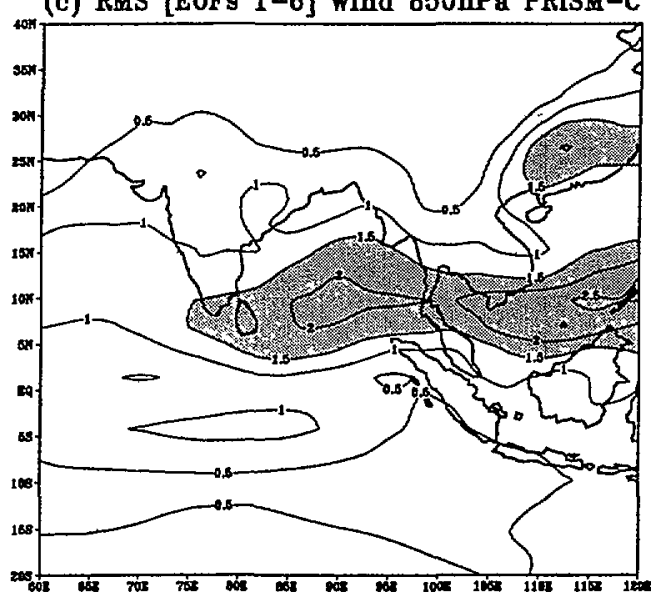

(d) RMS [EOFs 1-6] prec CMAP

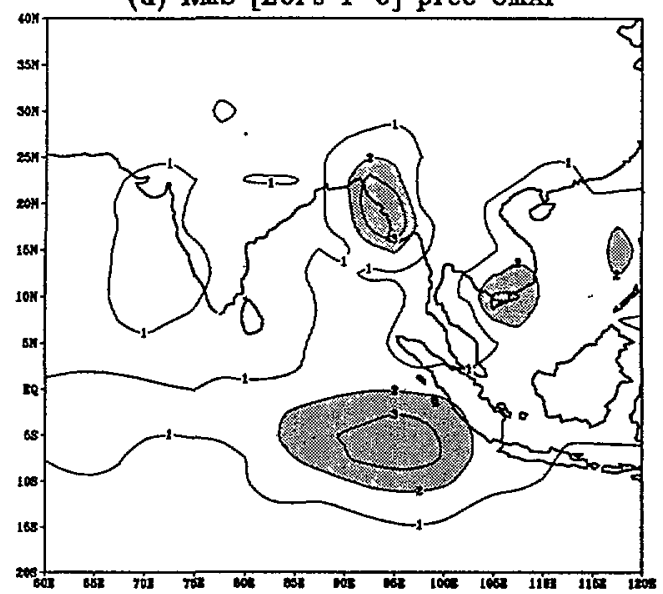

(e) RMS [EOFs 1-6] prec PRISM-0

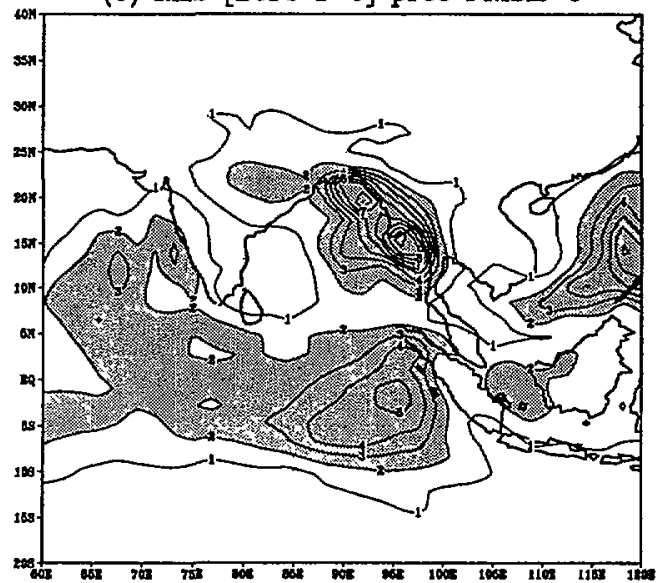

(f) RMS [EOFs 1-6] prec PRISM-C

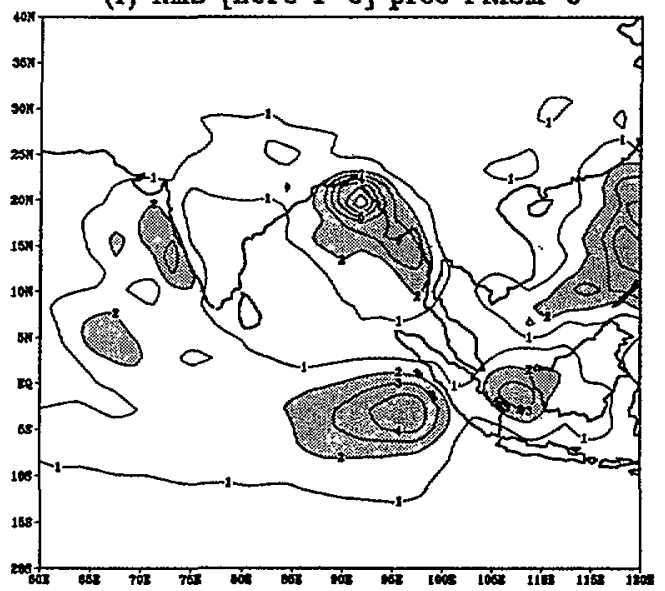

Figure 1: Spatial distribution of the rms amplitude of seasonal anomalies projected on the 6-EOF subspace: (a) $850-\mathrm{hPa}$ wind from the NCEP reanalysis dataset; (b) as in (a) from PRISM-O integrations; (c) as in (b) from PRISM-C; (d) precipitation from the CMAP dataset; (e) as in (d) from PRISM-O integrations; (f) as in (e) from PRISM-C. Wind units: $\mathrm{m} / \mathrm{s}$ (contours every $0.5 \mathrm{~m} / \mathrm{s}$, shading above $1.5 \mathrm{~m} / \mathrm{s}$ ). Precipitation units: $\mathrm{mm} /$ day (contours every $1 . \mathrm{mm} /$ day, shading above 2 $\mathrm{mm}$ (day). 
(a) NCEP RA 1979/98 $850 \mathrm{hPa}$ wind EOF1

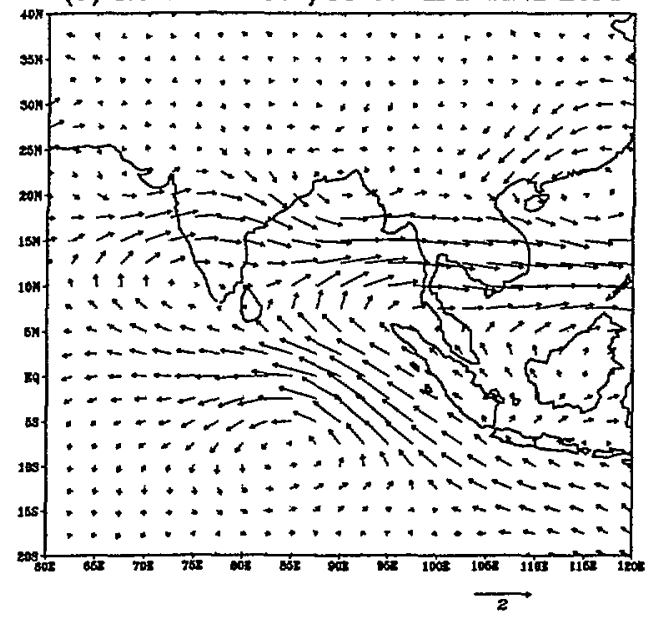

(b) NCEP RA 1979/98 $850 \mathrm{hPa}$ wind EOF2

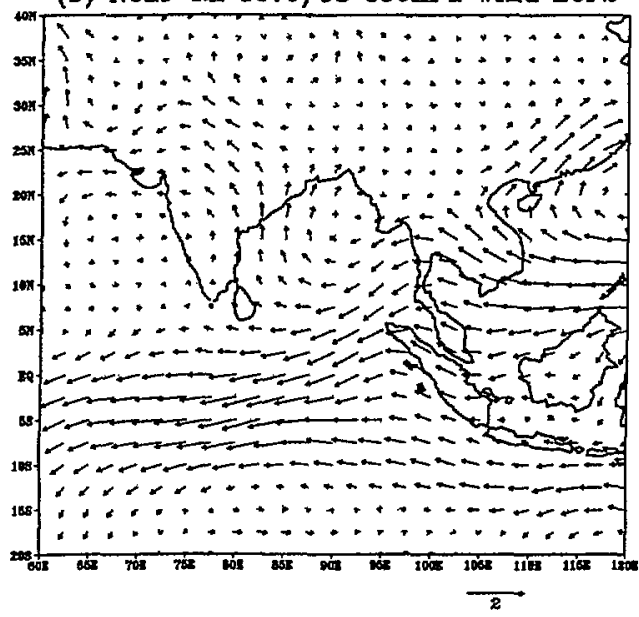

(c) NCEP RA $1979 / 98850 \mathrm{hPa}$ wind EOF3

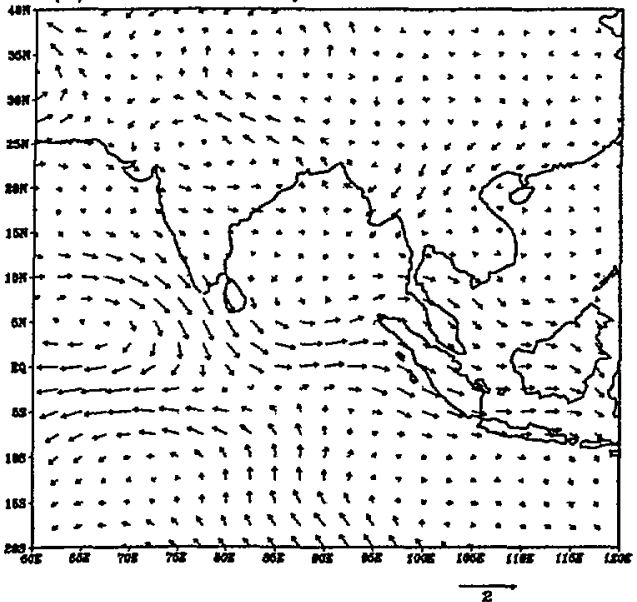

(d) PRISM-0 850hPa wind EOF1

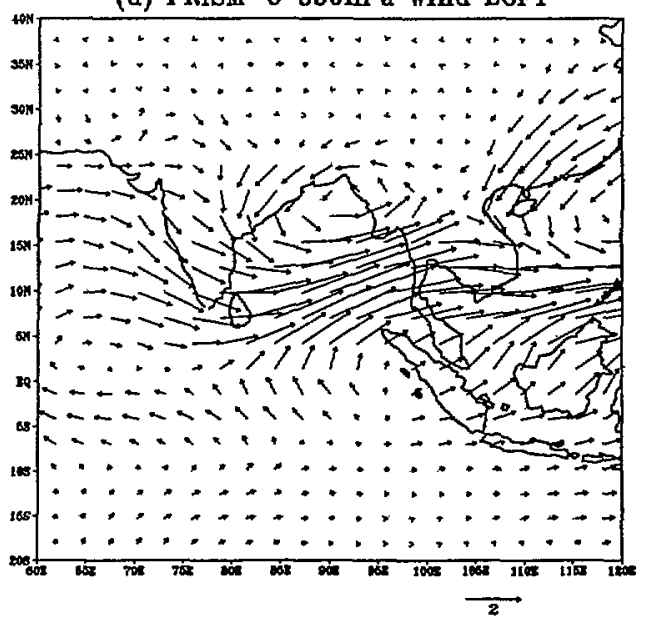

(e) PRISM-0 850hPa wind EOF2

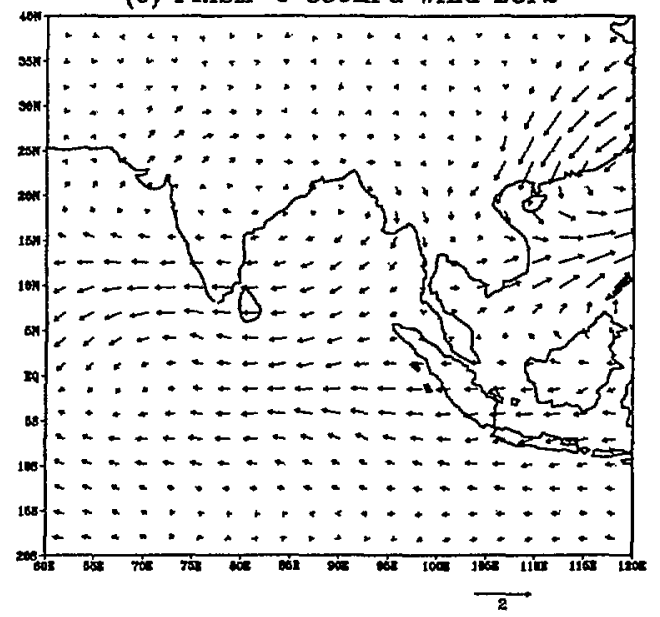

(f) PRISM-0 $850 \mathrm{hPa}$ wind EOF3

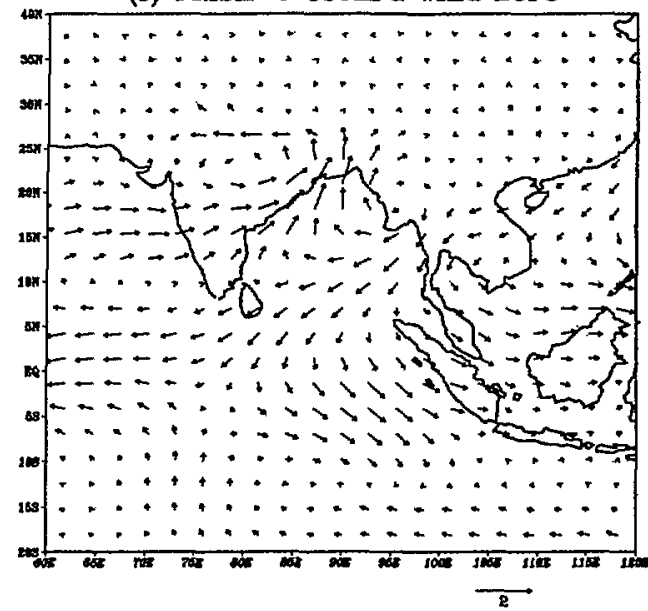

Figure 2: Leading three EOFs of $850-\mathrm{hPa}$ wind anomalies. Left column (panels (a)-(b)-(c)): from the NCEP reanalysis dataset. Right column (panels (d)-(e)-(f)): from PRISM-O integrations. These EOFs (scaled by the squared-root of the explained variance) represent the anomaly associated with one standard deviation of the associated principal components. Units: $\mathrm{m} / \mathrm{s}$. 
(a) CMAP $1979 / 98$ prec EOF 1

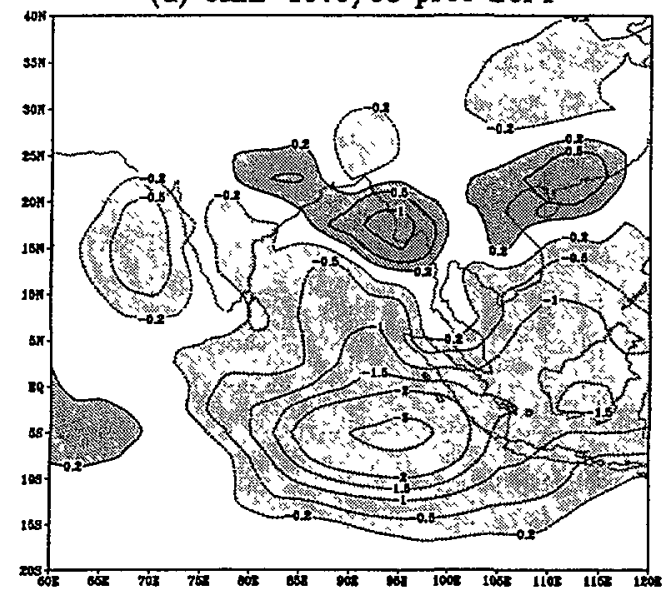

(b) CMAP 1979/98 prec EOF2

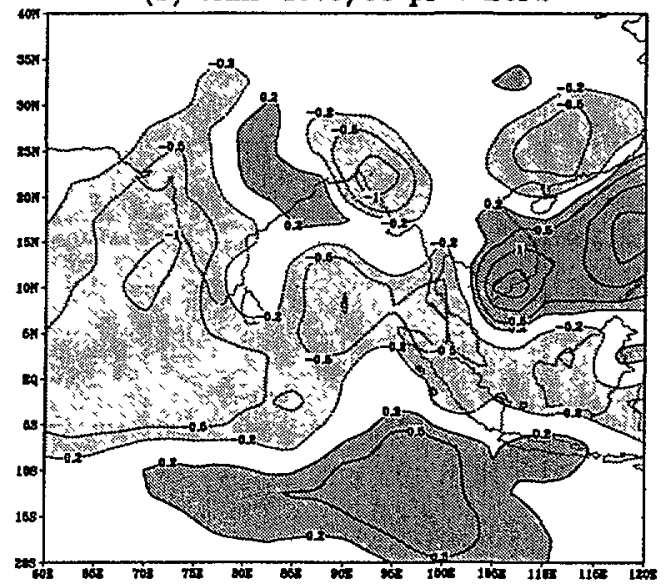

(c) CMAP 1979/98 prec EOF3

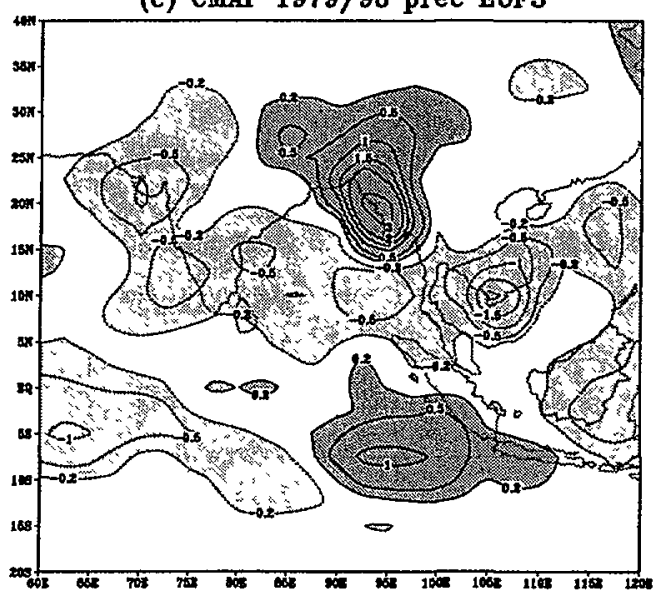

(d) PRISM-0 prec EOF 1

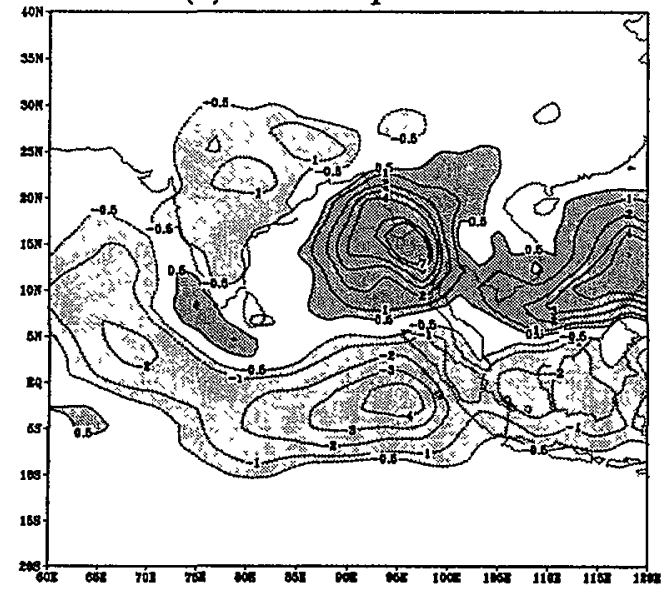

(e) PRISM-0 prec EOF2

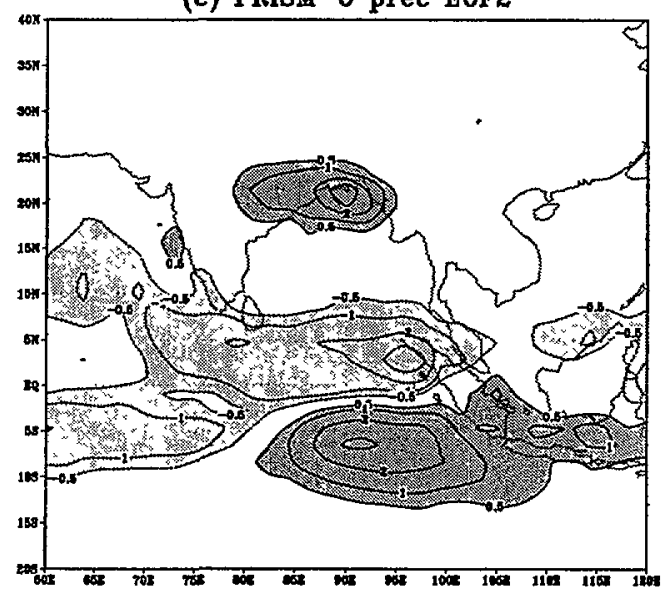

(f) PRISM-0 prec EOF3

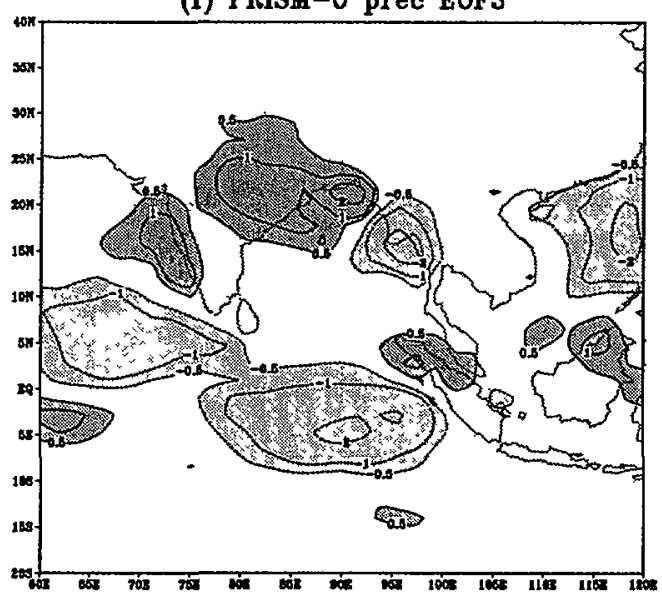

Figure 3: As in Fig.2, but for rainfall anomalies. Left column (panels (a)-(b)-(c)): from the CMAP dataset; units: $\mathrm{mm} /$ day; light/dark shading denotes anomalies below/above 0.2. Right column (panels (d)-(e)-(f)): from PRISM-O integrations; units: $\mathrm{mm} /$ day; light/dark shading denotes anomalies below/above 0.5 . 


\section{(a) PRISM-C $850 \mathrm{hPa}$ wind EOF1}

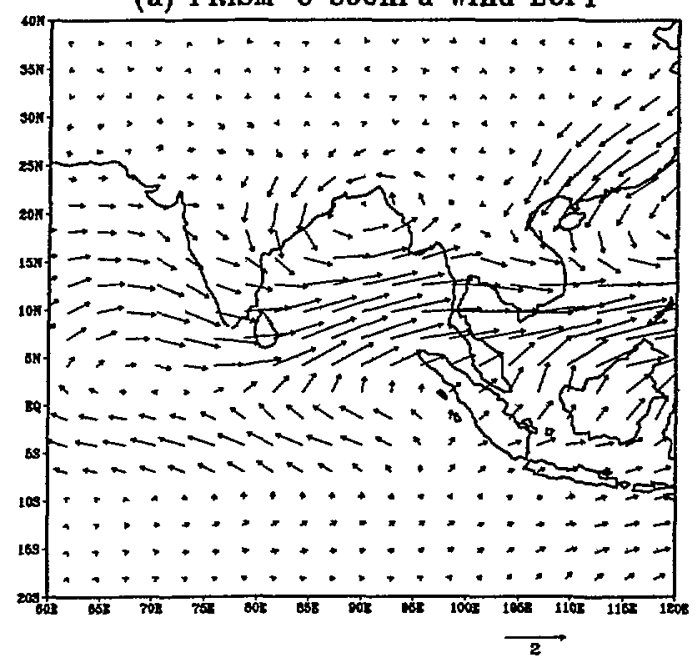

(b) PRISM-C prec EOF1

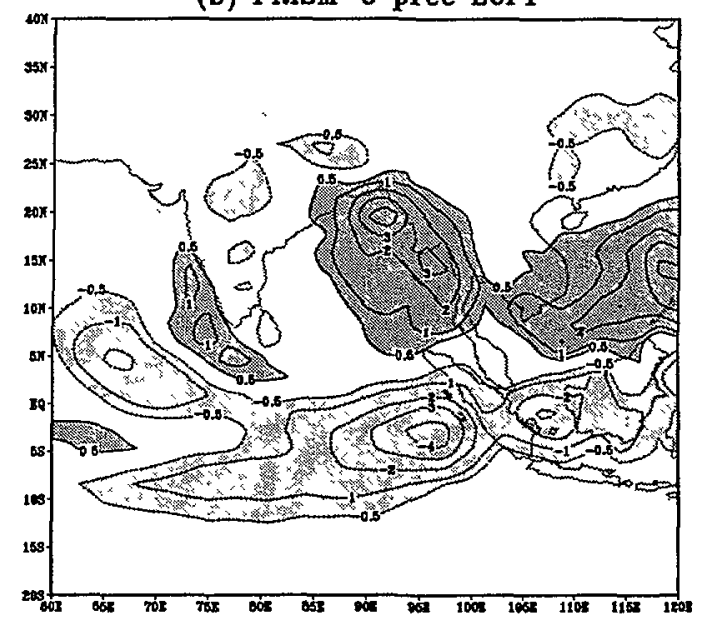

Figure 4: EOF1 from PRISM-C integrations. (a) 850-hPa wind anomalies; units: $\mathrm{m} / \mathrm{s}$. (b) Rainfall anomalies; units: $\mathrm{mm} /$ day; light/dark shading denotes anomalies below/above 0.5 . 
(a) PRISM-0 850hPa wind SVD1

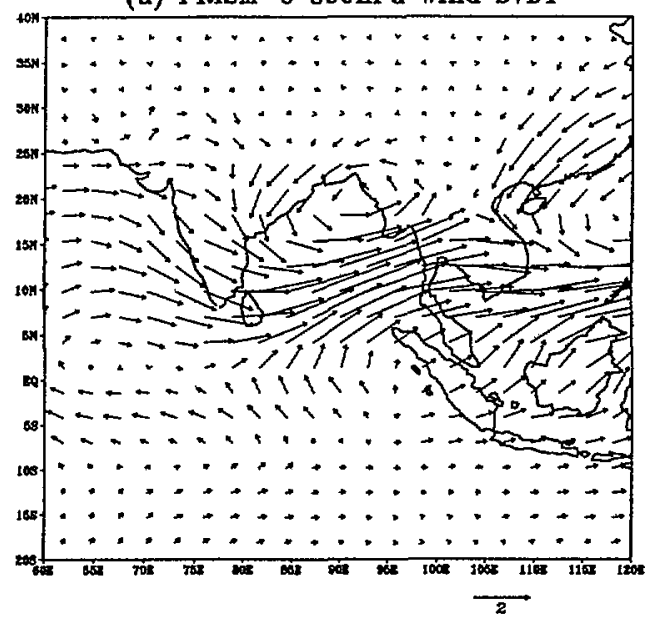

(b) PRISM-0 850hPa wind SVD2

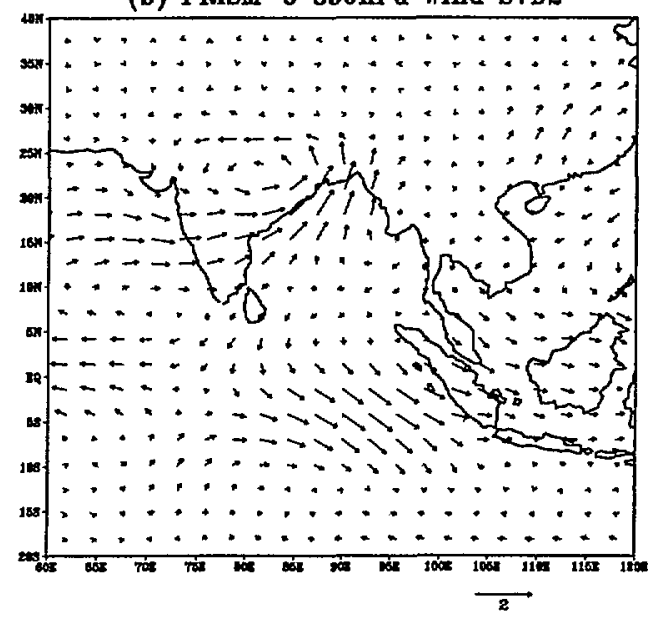

(c) PRISH-C $850 \mathrm{hPa}$ wind SVD2

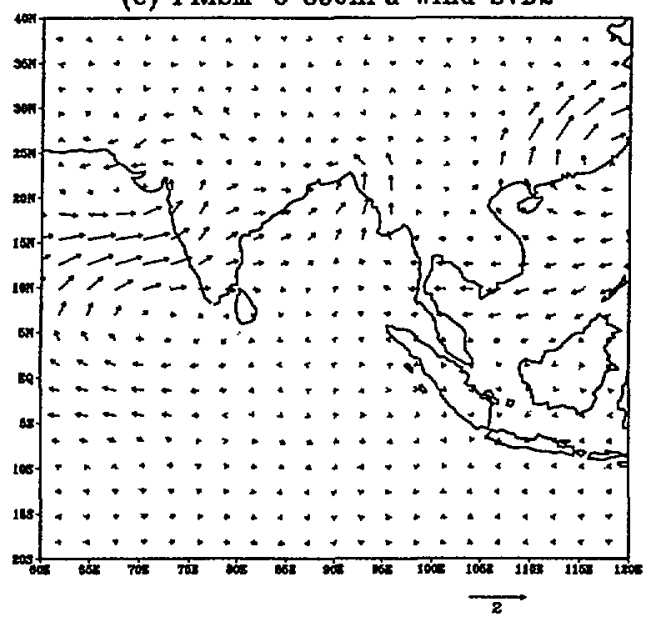

(d) PRISM-O prec SVD1

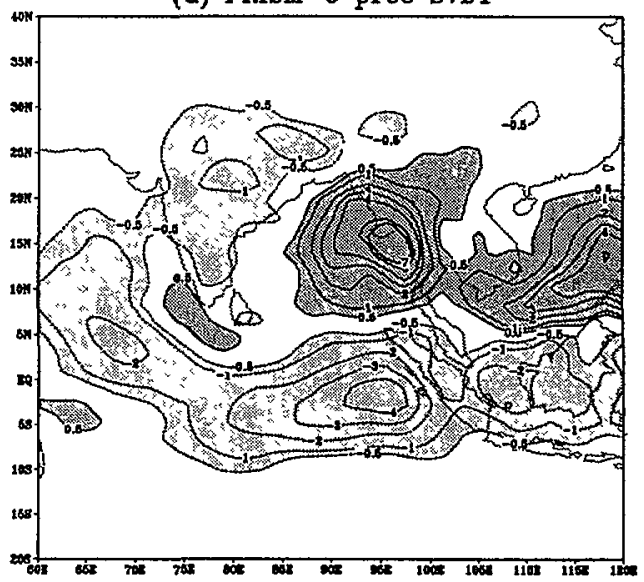

(e) PRISM-0 prec SVD2

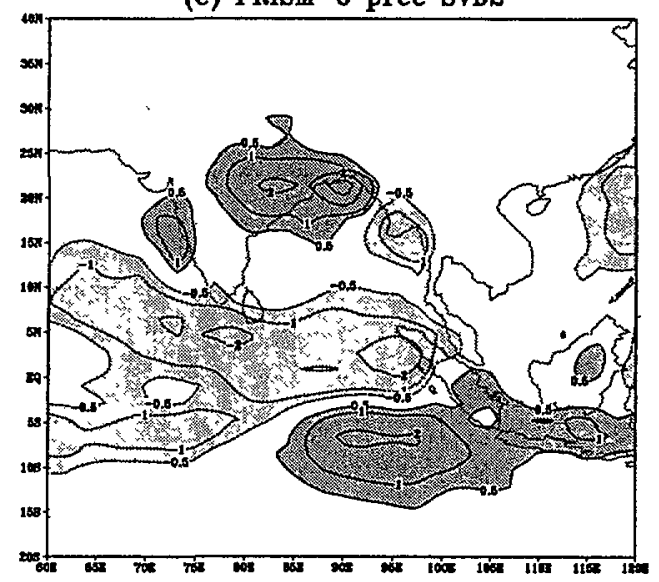

(f) PRISM-C prec SVD2

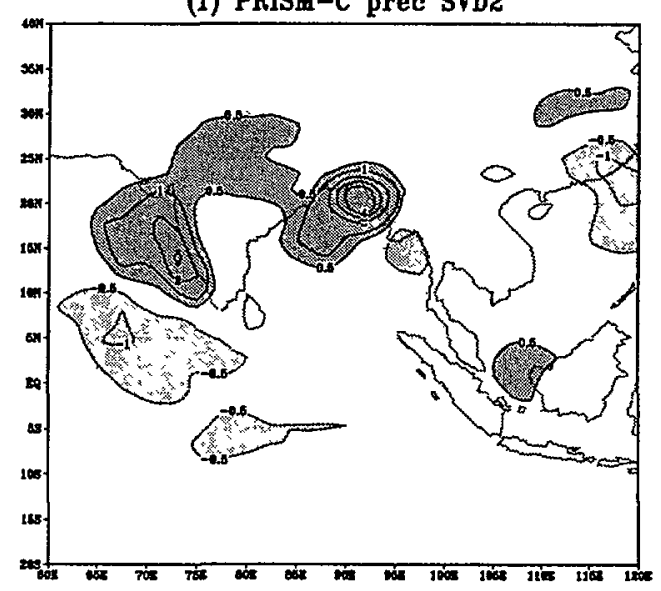

Figure 5: Singular Value Decomposition (SVD) patterns of 850 -hPa wind and rainfall anomalies in the PRISM experiments. Left column: $850-\mathrm{hPa}$ wind anomalies for the leading two SVD modes of PRISM-O ( $a, b)$ and the second SVD mode of PRISM-C (c); (units: $\mathrm{m} / \mathrm{s}$ ). Right column: rainfall anomalies for the leading two SVD modes of PRISM-O (d, e) and the second SVD mode of PRISM-C (f); (units: $\mathrm{mm} /$ day; light/dark shading denotes anomalies below/above 0.5 ). 
(a) Cor. SST Feb - SVD1 mind850 PRISM_0

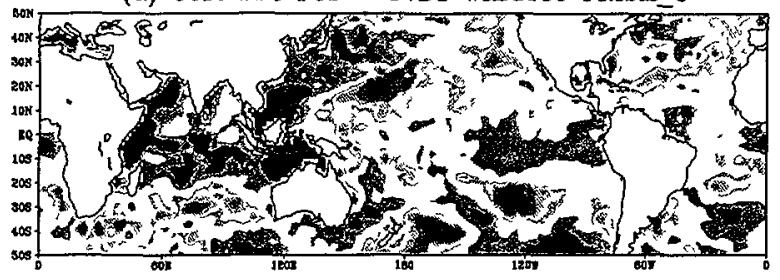

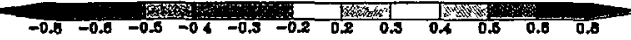

(b) Cor. SST Apr - SVD1 wind850 PRISM_o

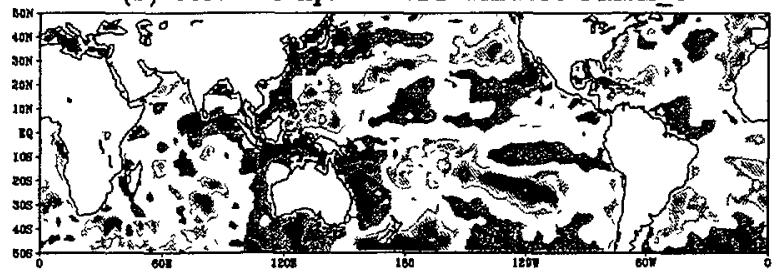

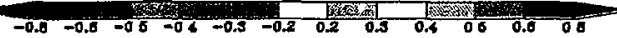

(c) Cor. SST Jun - SVD1 wind850 PRISM_0
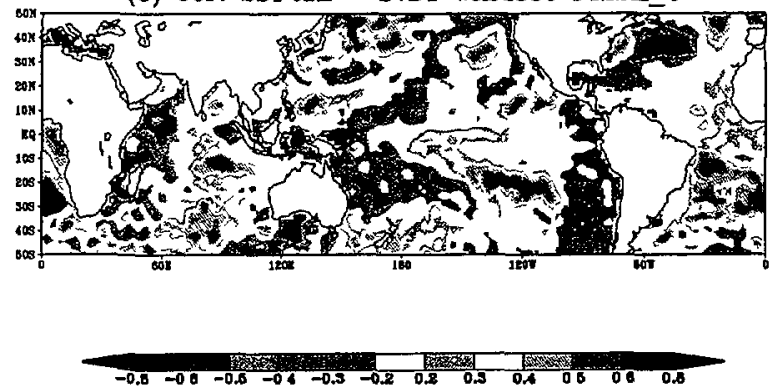

(d) Cor. SST Aug - SVD1 mind850 PRISM_O

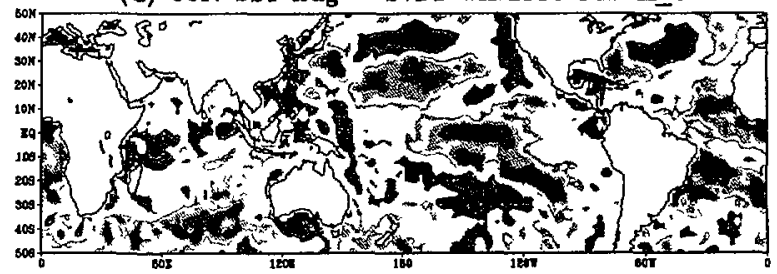

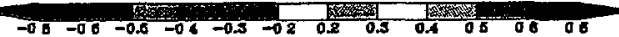

Figure 6: Correlation patterns between the ensemble mean values of time coefficients associated with the first $850-\mathrm{hPa}$ wind SVD mode of PRISM-O (i.e. the rotated PC) and SST anomalies in February (a), April (b), June (c) and August (d).

(a) Cor. SST Feb - SVD2 uv850 PRISM_0

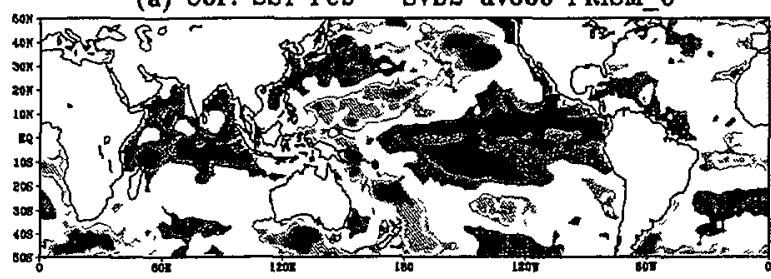

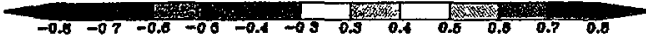

(b) Cor. SST APr - SVD2 uv850 PRISM_O

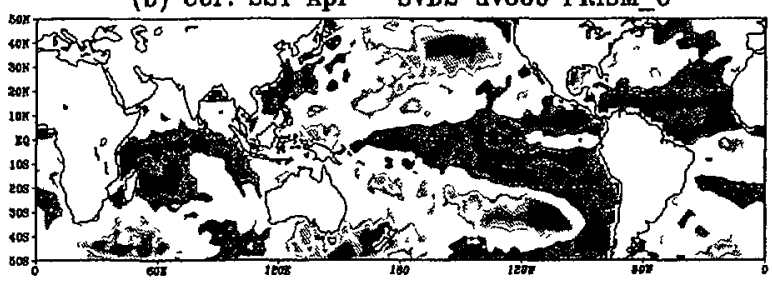

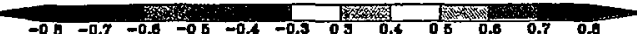

(c) Cor. SST Jun - SVD2 uv850 PRISM_o
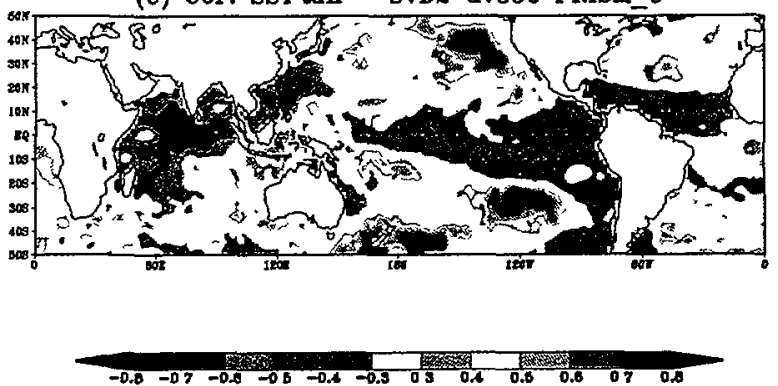

(d) Cor. SST Aug - SVD2 uvB50 PRISM_O

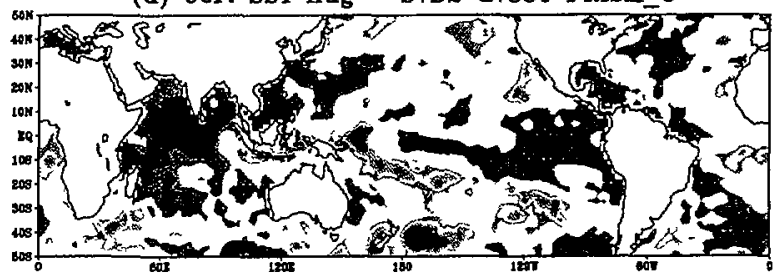

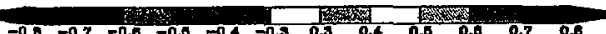

Figure 7: As in Fig.6, but for the rotated PC associated with the second 850-hPa wind SVD mode of PRISM-O. 
(a) wind850 PRISM-0 SVD1

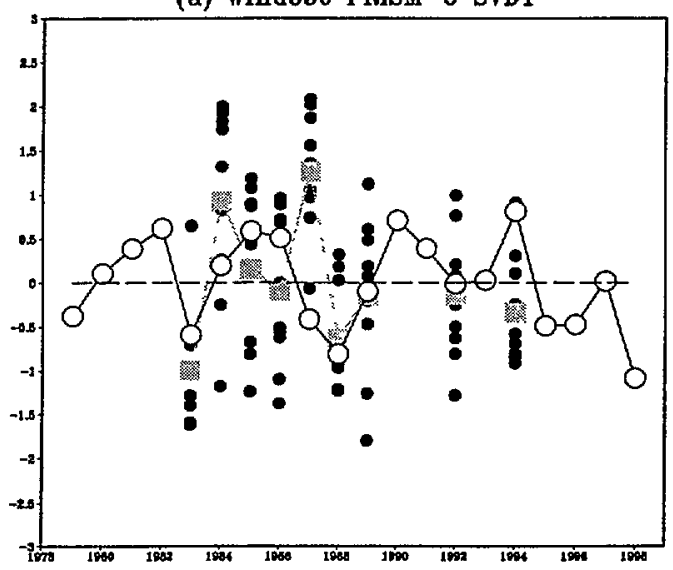

(b) rind850 PRISM-0 SVD2

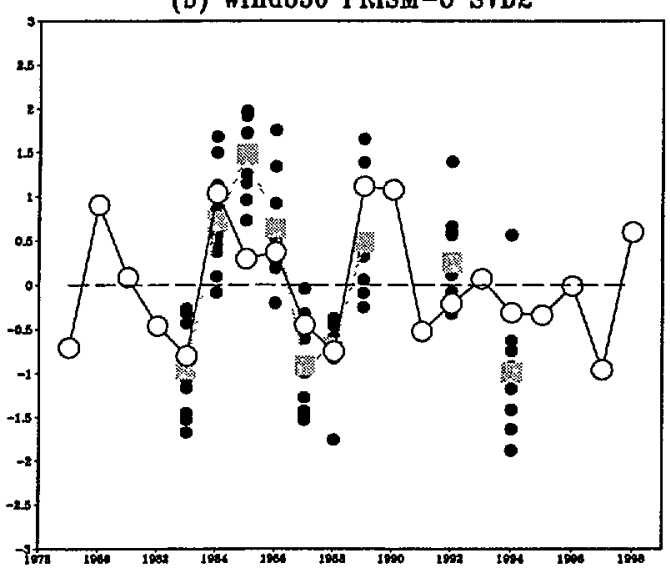

(c) prec PRISM-0 SVD1

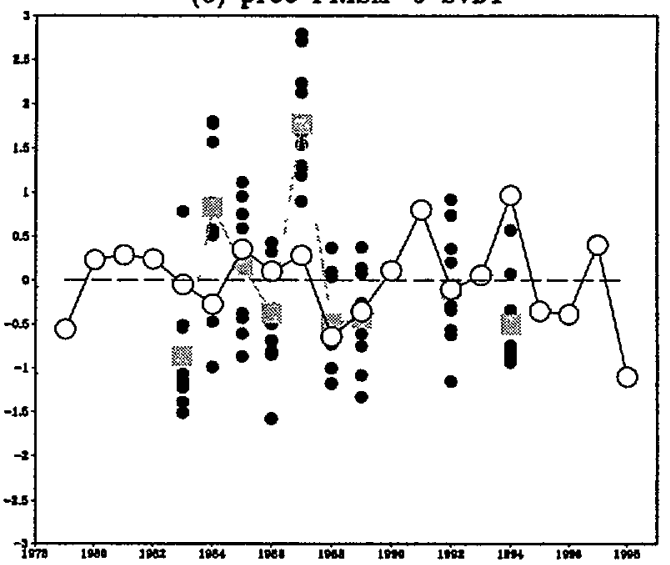

(d) prec PRISM-0 SVD2

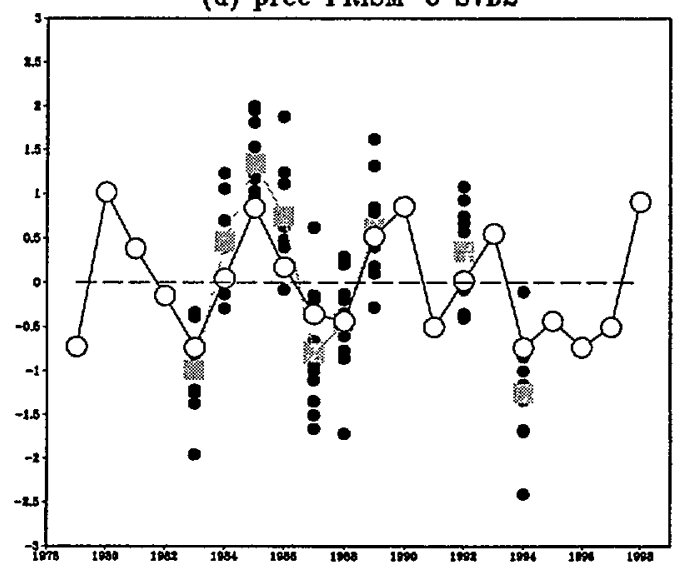

Figure 8: Time series of the rotated PCs associated with the two SVD modes for 850-hPa wind and rainfall. Each model integration is represented by a black dot. The grey solid squares denote the average over the ten members of each ensemble. The open circles mark the projections of observed anomalies on the same SVD patterns (see text for further details). (a) 850-hPa wind SVD1; (b) 850-hPa wind SVD2; (c) rainfall SVD1; (d) rainfall SVD2. 
(a) wind850 PRISM-C onto PRISM-0 SVD1

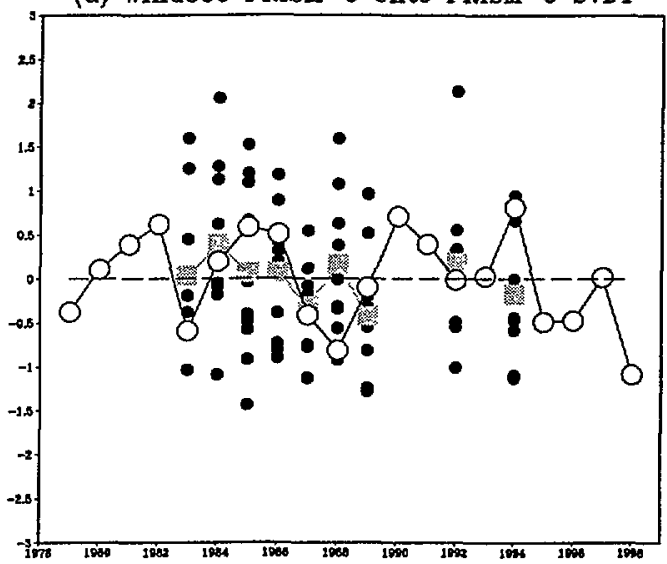

(b) wind850 PRISM-C onto PRISM-0 SVD2

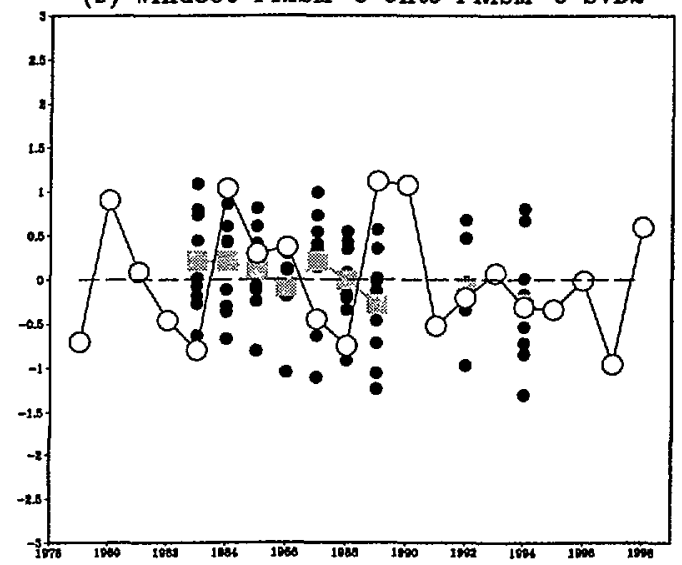

(c) prec PRISM-C onto PRISM-0 SVD1

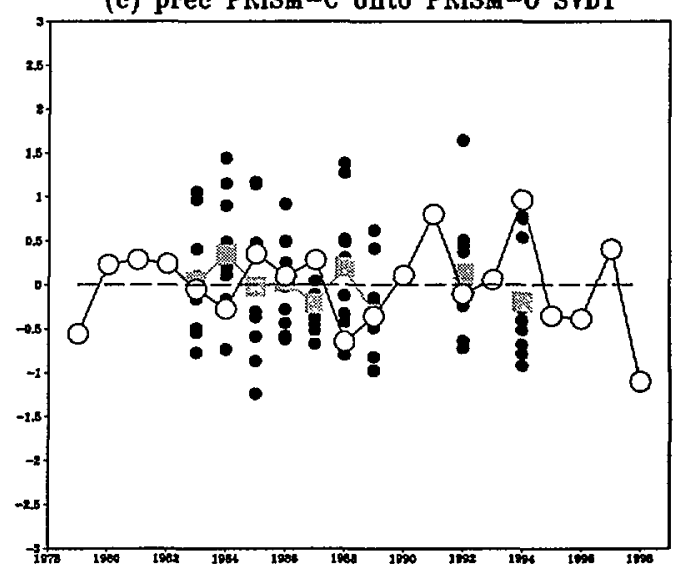

(d) prec PRISM-C onto PRISM-0 SVD2

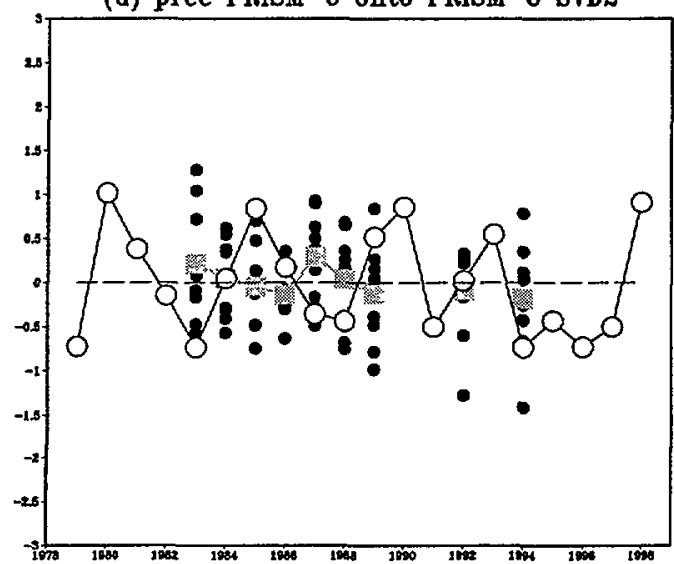

Figure 9: As in Fig.8, but for the time series of the projections of model anomalies from PRISM-C onto the PRISM-O SVD patterns shown in Fig.5. Each PRISM-C anomaly projection is represented by a black dot. The grey solid squares denote the ensemble mean projection. The open circles are the same as in Fig.8. (a) $850-\mathrm{hPa}$ wind SVD1; (b) $850-\mathrm{hPa}$ wind SVD2; (c) rainfall SVD1; (d) rainfall SVD2. 
(o) RMS [EOFs 1-6] $5 d-m$ prec (intras.) CMAP

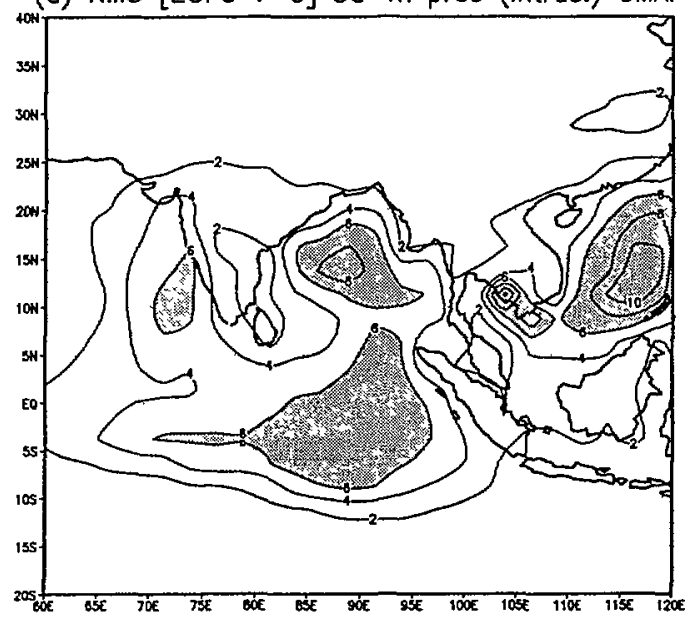

(b) RMS [EOFs 1-6] 5d-m prec PRISM-O

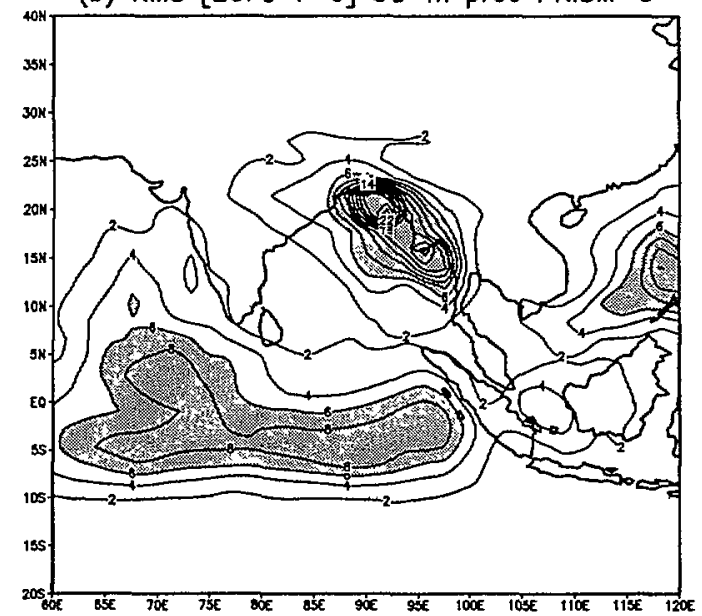

Figure 10: Spatial distribution of the rms amplitude of 5-day mean rainfall anomalies projected on the 6-EOF subspace: (a) from the pentad CMAP dataset ; (b) from PRISM-O integrations. Units: $\mathrm{mm} /$ day (contours every $2 . \mathrm{mm} /$ day, shading above $6 \mathrm{~mm} /$ day). 
(a) PRISM-0 5d-m prec EOF 1

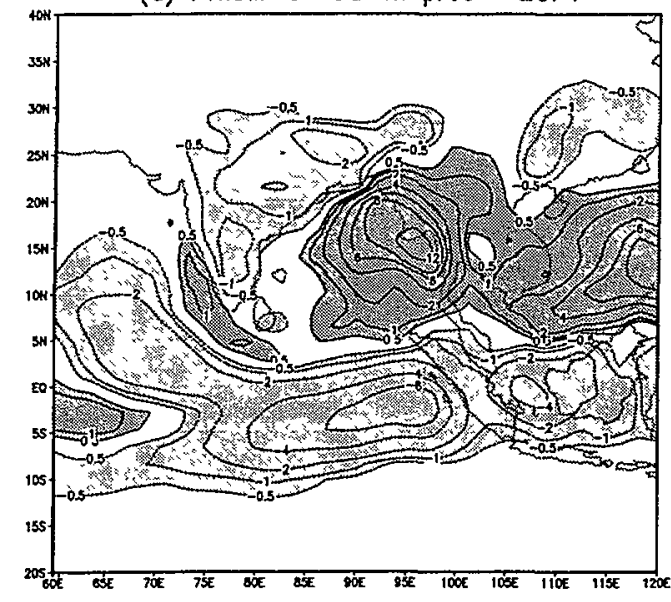

(b) PRISM-0 5d-m prec EOF2

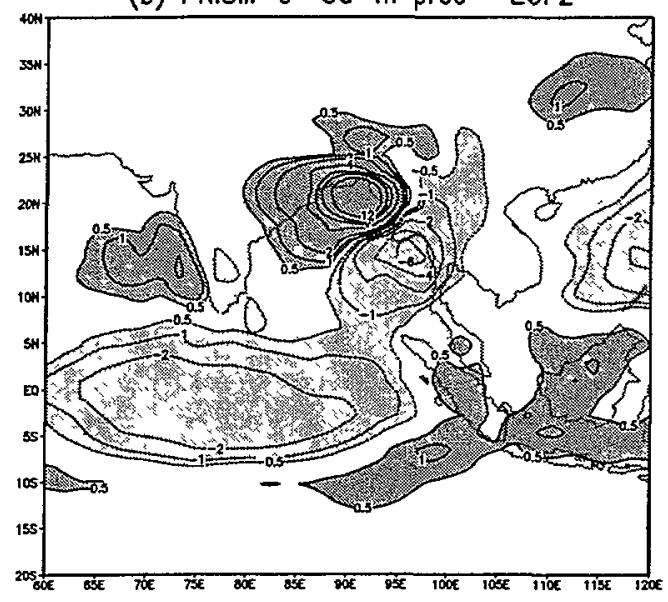

(c) PRISM-O $5 d-m$ prec (intras.) EOF1

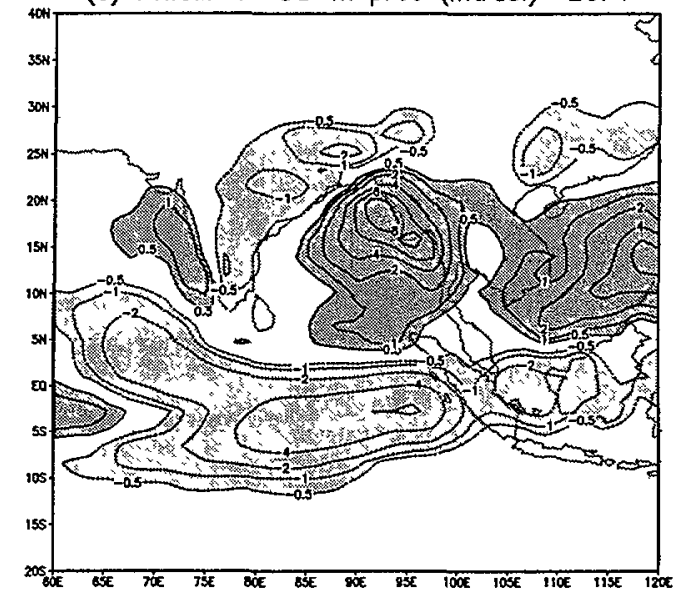

(d) PRISM-O $5 d-m$ prec (intras.) EOF2

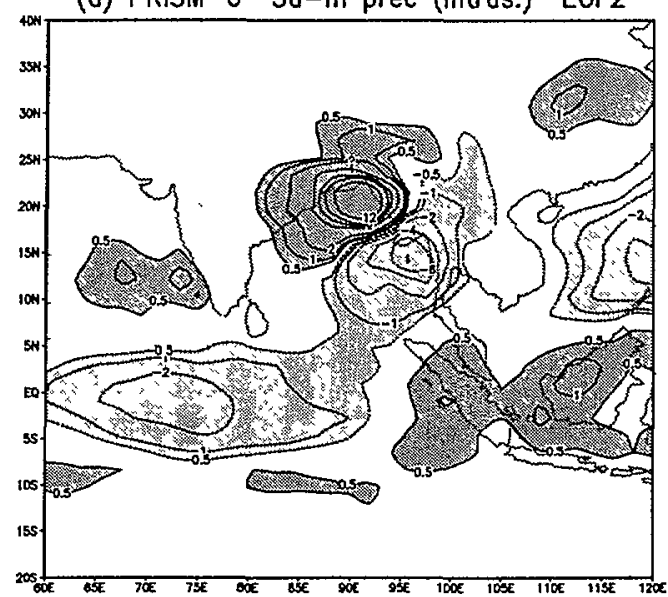

Figure 11: Leading two EOFs of pentad rainfall from PRISM-O integrations. Left column (panels (a)-(b)): EOFs of total anomalies. Right column (panels (c)-(d)): EOFs of the intraseasonal anomalies. Units: $\mathrm{mm} /$ day; light/dark shading denotes anomalies below/above 0.5 . 


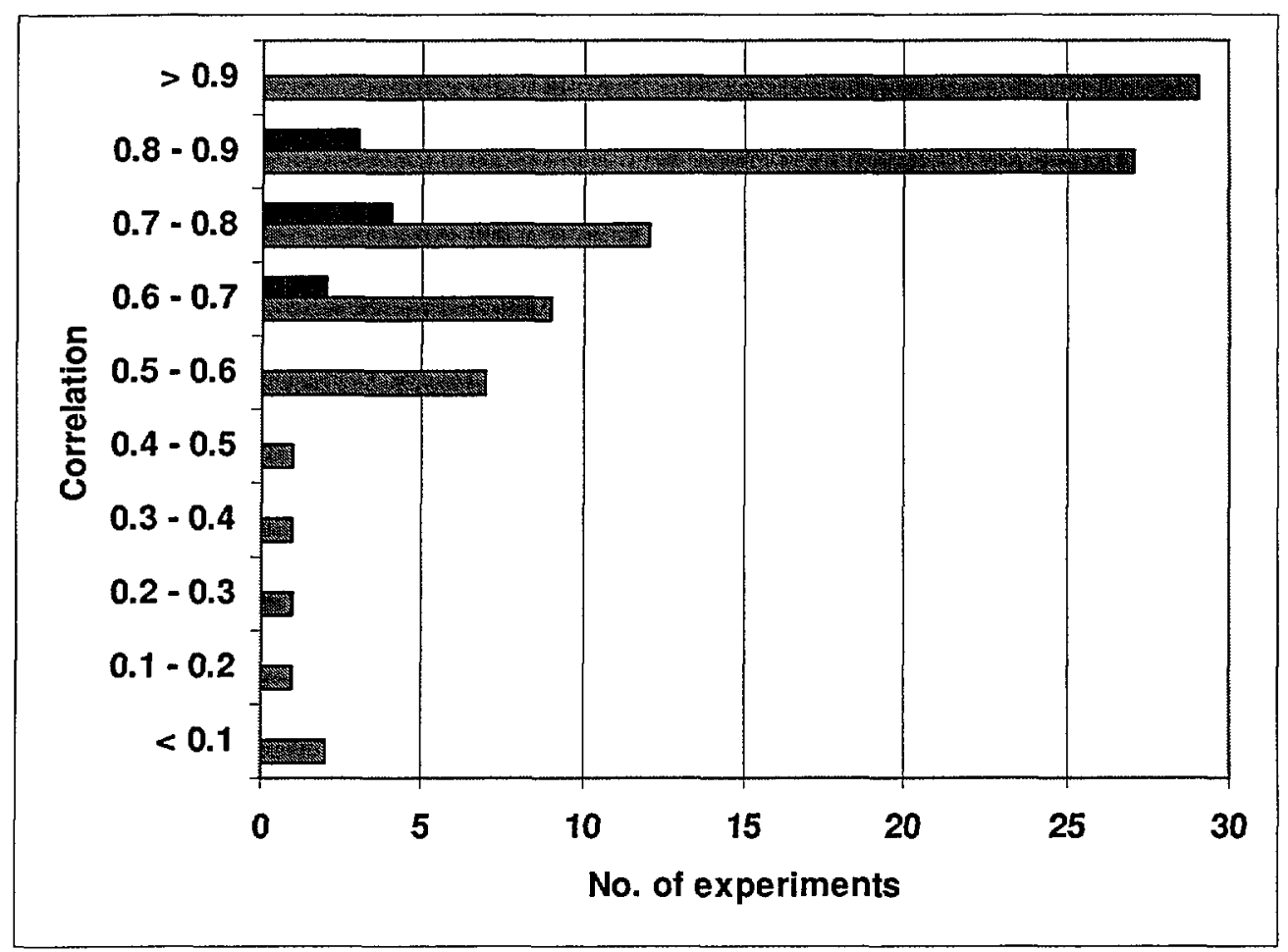

Figure 12: Distribution of spatial correlations between projections of seasonal-mean rainfall anomalies onto the first two SVD rainfall patterns (Fig. 5c-d) and the first two EOFs of intraseasonal rainfall (Fig. 11c-d), for individual PRISM-O experiments (light shading) and for ensemble means (dark shading). 
(a) PDF (pc1, pc2) 5d-m prec PRISM-O

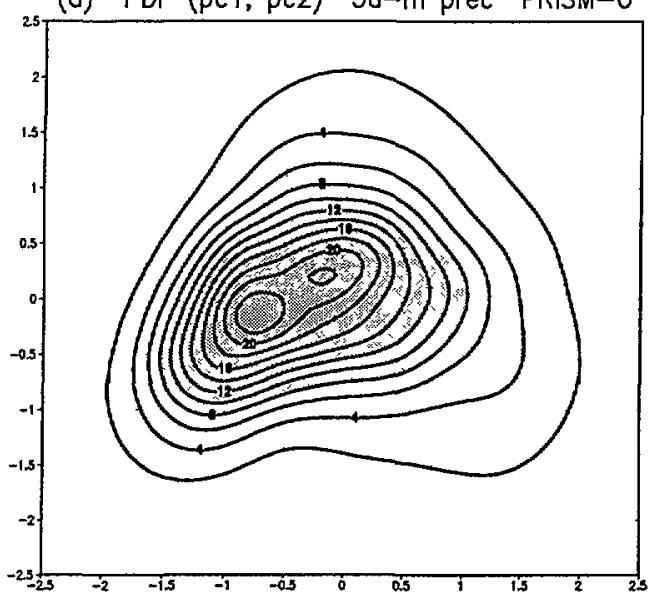

(b) cold ENSO $(84,85,88,89)$

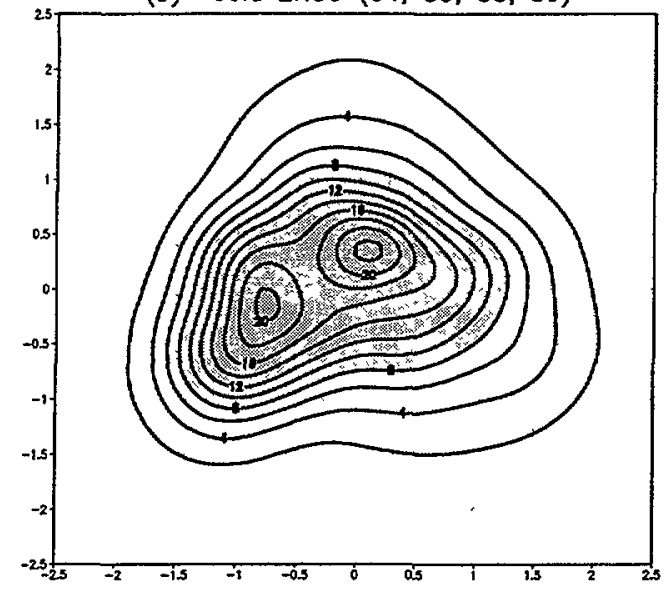

(c) warm ENSO $(83,86,87,92,94)$

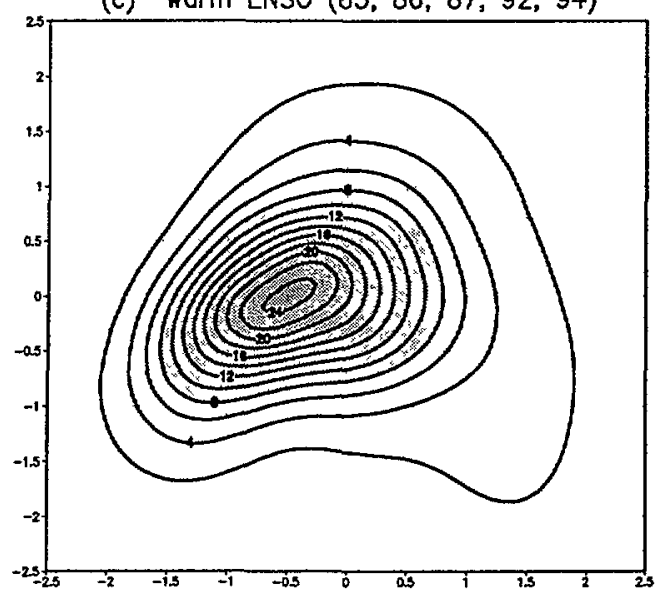

(d) cold - worm ENSO

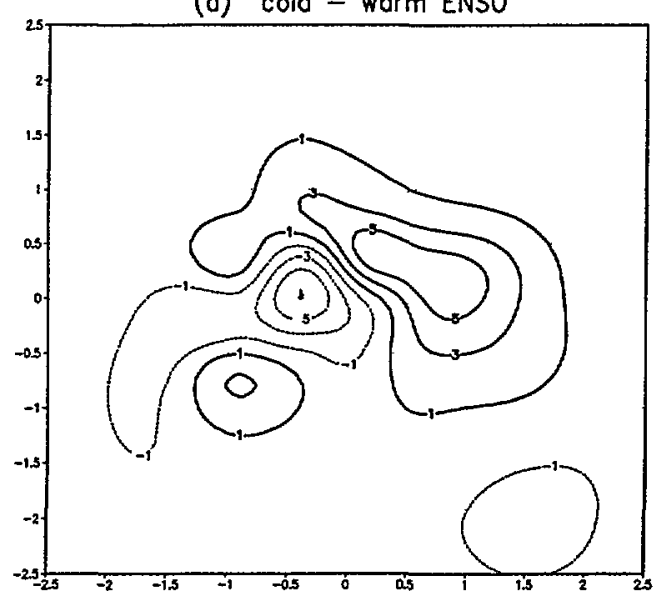

(e) PDF (Pc1) cold vs. warm ENSO

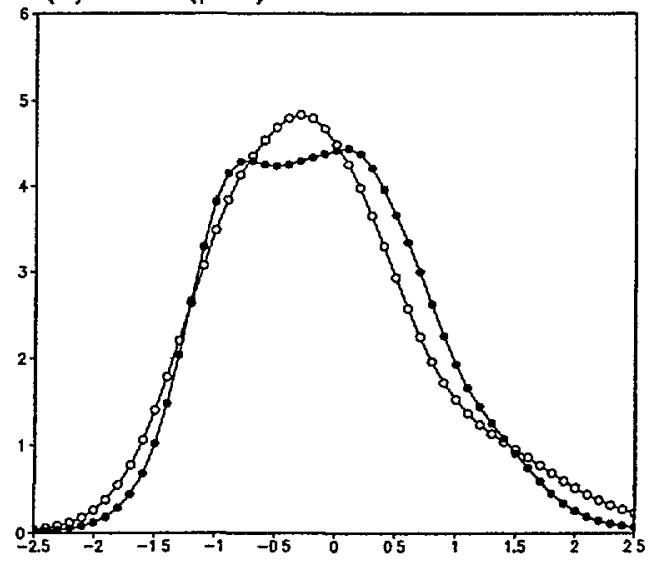

Figure 13: Probability density functions (PDFs) of the two leading principal components of pentad rainfall from PRISM-O integrations. (a): Bi-dimensional PDF in the (PC1, PC2) phase space for the 90 PRISM-O simulations (whole sample) estimated with $h=0.30$. (b): As in (a) but for the subsample of cold ENSO summers estimated with $h=0.35$. (c) As in (a) but for the subsample of warm ENSO summers [h=0.35]. (d) Difference between panels (b) and (c). (e): One-dimensional PDF in the PC1 phase space; solid circles: subsample of cold ENSO summers; open circles: subsample of warm ENSO summers. 